\title{
Dos forjadores de las Ciencias Sociales en el Perú: SUS PUBLICACIONES Y CONFRONTACIONES

\author{
O. Gabriel Prieto Burmester*
}

\section{Resumen}

En este artículo se analiza las causas y confrontaciones entre Julio C. Tello y Luis E. Valcarcel en los primeros años de la arqueología institucionalizada del Perú. En el proceso se estudia las diversas fuentes, medios y conexiones políticas usadas por estos investigadores con el afán de ejercer sus carreras pero al mismo tiempo su interés por fomentar el desarrollo de las Ciencias Sociales en el Perú.

Palabras clave

Tello, Valcárcel, Historia de la Arqueología, Política arqueológica.

\begin{abstract}
This article analyses the confrontations between Julio C. Tello and Luis E. Valcárcel and their causes. It also explores the diverse sources, media and political connections used by Tello and Valcárcel in pursuing their work during their careers. At it does so, it explores their interests and efforts in promoting the development of the Social Sciences in Peru.
\end{abstract}

Keywords

Tello, Valcárcel, History of Archaeology, Politics of Archaeology.

* Estudiante de Doctorado en Arqueología del Departamento de Antropología, Yale University. Correo electrónico: oscar.prieto@yale.edu 
En el presente ensayo vamos a discutir algunos aspectos relacionados a la vida de Julio C. Tello y Luis E. Valcárcel. No vamos a resumir sus biografías pues sobre ello existe bibliografía especializada. Tampoco vamos a describir sus trabajos publicados. En este ensayo se va discutir sobre dos aspectos que creemos fundamentales para a) tener una perspectiva clara de las relaciones políticas y sociales que conllevaron a ambos personajes a consagrarse como intelectuales orgánicos y b) analizar y describir el contexto en el cual se desarrollaron. Para ello hemos creído conveniente analizar preferentemente el año 1930 que es cuando ambos comenzaron a trabajar juntos por espacio de 17 años hasta la muerte de Tello en 1947. Del mismo modo, analizamos las coyunturas que se les presentaron a ambos antes y después de 1930.

El concepto de Latin American Organic Intellectual (LAOI) gira en torno a dos grandes esferas. La primera es una esfera de producción intelectual que en el caso de la antropología, el factor central fue la comprensión de la sociedad viva, la sociedad pasada y la interrelación existente entre ambas. Si bien es cierto existen casos de LAOI en varios países latinoamericanos, son los relacionados a México y el Perú los que mas han repercutido socialmente. El proceso de aculturación en ambos países (que de acuerdo a muchos de los LAOI está en pleno proceso de desarrollo) generó a inicios del siglo XX patrias huérfanas de una historia propia, avergonzadas erróneamente de un pasado colonial y con una fuerte tendencia a tratar de resolver el problema del indio, manifestado luego en los movimientos indigenistas de arte, literatura y política. Posteriormente fue allí donde encontró su nicho (io acaso origen?) la arqueología y antropología por ser los gestores de la comprensión de estas poblaciones oprimidas durante siglos. Las políticas adoptadas fueron distintas en cada país, siendo México con Manuel Gamio y la facilidad de un gobierno que aplicó muchos de los principios e ideas planteadas por este movimiento, aunque luego Bonfil criticó duramente ese proceso y su "desastroso" resultado (Bonfil 1981). En el caso del Perú, el presidente Leguía adoptó una tendencia de apoyo al indígena y a la labor científi- ca de Tello (Masia 2006). Las políticas se encauzaron en propiciar la generación de una identidad nacional basada en el pasado prehispánico (Leguia 2006). Tello tuvo una fértil producción política durante sus años de diputado leguiísta, sentando las bases legales para la protección y conservación del patrimonio prehispánico (Burger 2009: 83) y la reorganización de la educación universitaria en Lima (Tello 1928). No obstante, el marcado centralismo del gobierno de Leguía impidió que esta perspectiva se expanda a otras regiones del país. Tello fue cada vez enfocando más su atención en actividades estrictamente académicas y arqueológicas, lo cual se materializó en las múltiples expediciones que realizó a lo largo de su carrera (Caballero 2007). El fin del "Oncenio" " produce un quiebre en la dirección de la política nacional y con eso Tello pierde todo apoyo y soporte político. Los gobiernos que vendrán sucesivamente entre 1930 y 1948 serán propicios para Luis E. Valcárcel, quien tras un periodo "radical" de tendencia indigenista, va a ir paulatinamente encausando sus propuestas a través de los gobiernos de turno para aplicar sus ideas y proyectos. Esto se puede observar en la institucionalización de la etnología en el Perú con el objeto de estudiar las costumbres y modos de vida de los pobladores rurales. Con ello, se pretendía incluirlos en el campo de acción del Estado, donde la educación sería la piedra angular de este proceso (Valcárcel 1946a). Si bien es cierto el ambicioso proyecto de Valcárcel incluyó el dictado de clases en idiomas nativos enfatizando una enseñanza técnica adaptada a la realidad de cada pueblo y región, ésta terminó siendo absorbida por la burocracia estatal.

La segunda esfera es la de producción intelectual, en la que todos los LAOI estuvieron de una u otra forma ligados al problema del indio en tanto las condiciones políticas y socio económicas apuntaban al desarrollo de esta población por una serie de razones que iban desde las más alturadas propuestas idealistas hasta los mas viles propósitios políticos y proselitistas. La presencia de dos grandes como Tello y Valcárcel, tuvo una

1 Fue el nombre con que se bautizó los 11 años del segundo gobierno de Augusto B. Leguía (1919-1930). 
repercusión definitivamente intelectual y política en la creación y en el ejercicio de las ciencias sociales en el Perú. Del mismo modo, al ser personajes excepcionales es evidente que comprendieron la escala de su repercusión en la historia no solo de su disciplina, sino en la historia de su país y del continente en general. Resulta interesante detenernos un momento para evaluar el impacto de estos dos LAOI en la sociedad peruana. El caso mas interesante sea probablemente el de Julio C. Tello quien según Burger (2009) se ha convertido en un ícono no solo en el ambiente académico peruano, sino también como fuente de inspiración para aquellos que como el, llegan de la sierra trágica (en palabras de Valcárcel) y buscan un futuro en la gran ciudad. Burger ha enfatizado el factor que hoy muchas avenidas, colegios, clubes, instituciones no necesariamente relacionadas a la arqueología llevan el nombre de "Julio C. Tello" debido al impacto de su obra, así como el prototipo social que representó (Burger 2009: 65) (Fig. 1). Podríamos agregar algunos datos estadísticos a esta propuesta, la cual compartimos plenamente. El nombre de "Julio C. Tello" se utiliza actualmente en 45 avenidas y/o calles de 22 distritos de Lima Metropolitana. Sin embargo se puede notar una marcada ausencia en los barrios más exclusivos como San Isidro, Surco o La Molina. El único distrito que tiene dos calles con ese nombre es Miraflores, donde este intelectual residió. Los distritos de San Miguel y Pueblo Libre, que están asociados a la clase media de la ciudad presentan un total de 6 calles con el nombre de Tello. Debemos remarcar que estos distritos han estado muy ligados a la arqueología nacional debido a que en Pueblo Libre se encuentra el Museo de Antropología y Arqueología del Perú (fundado por Tello) y en San Miguel se encuentra uno de los complejos arqueológicos más importantes de la ciudad: el Complejo Maranga así como la ciudad universitaria de la Universidad Nacional Mayor de San Marcos, alma mater de Tello y donde se inició la enseñanza de arqueología en el país. Por otro lado, su incidencia es más acentuada en los distritos de clases bajas como El Agustino, Comas, Lurigancho, La Perla, Santa Anita, entre otros. Estos distritos son el resultado de millones de migrantes de todas la regiones del país y su descendencia, por lo que es correcta la reflexión de Burger acerca que Tello se ha convertido en un prototipo y un modelo a seguir por el éxito que alcanzó y por el mensaje que irradia su obra. En el caso de Valcárcel, su nombre es casi inexistente en la trama urbana de la capital peruana, pues solo existen dos calles en San Juan de Lurigancho.

LOS ANTECEDENTES DE TELLO Y VALCÁRCEL: SUS PERSPECTIVAS ACERCA "DEL" INDIO Y "LO" INDIO

Ambos intelectuales pertenecían a la sierra del país, a ese relicto de tradición al que nadie le prestaba atención a finales del siglo XIX, pero donde paradójicamente se habían suscitado los acontecimientos sociales y políticos más excitantes del Perú republicano. Por citar algunos

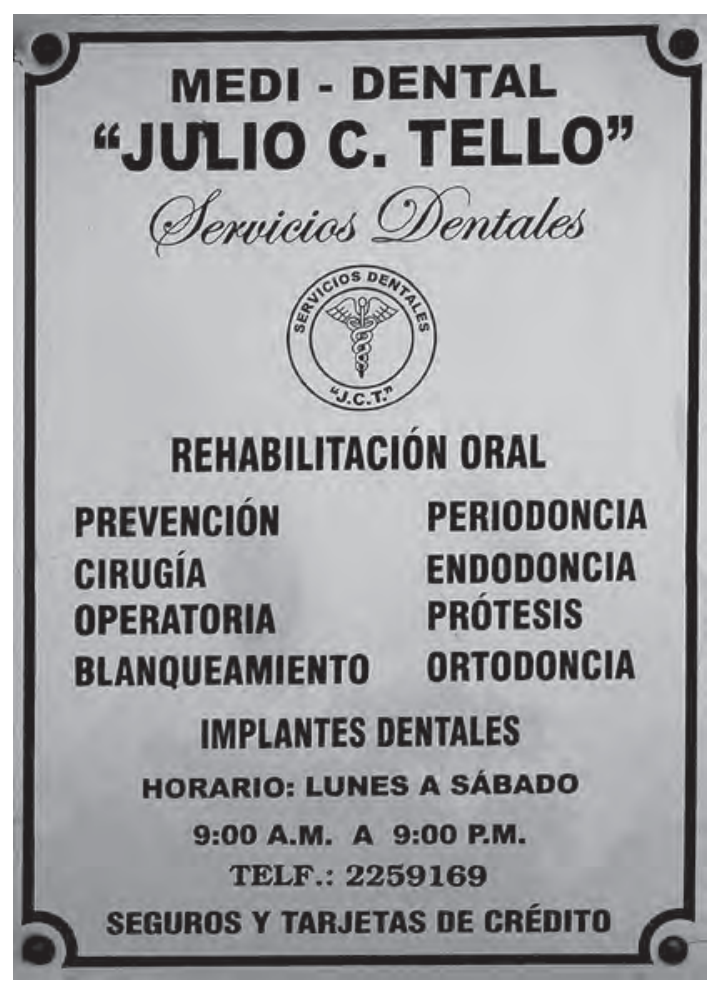

Figura 1: Placa de Clínica Dental denominada "Julio C. Tello". Evidentemente, el nombre del sabio arqueólogo trasciende los límites del ámbito cultural. Esta fotografía fue tomada en las inmediaciones de la Av. Madrid en San Jorja, Lima. 
ejemplos, las guerras de la independencia se consumaron en la sierra peruana y por otro lado las guerras por la sucesión del poder entre los primeros gobiernos de cabecillas militares fueron definidas en este ambiente. Finalmente uno de los eventos más catastróficos de la historia del Perú que fue la Guerra con Chile (Guerra del Pacífico), cuyas últimas batallas así como la resistencia de los patriotas se dio en las sierras de Huamachuco, Callejón de Huaylas y toda la zona de la sierra central y sur del país. Este conjunto de actividades debe haber calado hondo en el habitante de estas regiones, quienes parecerían haber asimilado más de la historia del Perú, que los propios costeños, debido a que básicamente ellos fueron actores de reparto dentro de estos episodios de sangre, derrota y victorias.

Tello y Valcárcel acusaron desde niños una promiscuidad académica con tendencia a las letras. Por un lado Tello fue seleccionado entre once hermanos para ir a estudiar a la capital, mientras que Valcárcel fue avocado tempranamente a la lectura y a la edad de 11 años ya escribía su propio periódico de política el cual distribuía entre sus amigos y compañeros. (Matos et al. 1981). Ambos dan sus primeros pasos en dos ambientes distintos: un pueblo de agricultores y el otro en una gran ciudad pero ubicada en el interior, casi olvidada en los inicios del siglo XX.

La familia Tello-Rojas fue de una condición social baja si es que se le compara con los Valcárcel-Vizcarra. A pesar que la familia de Tello tuvo relevancia política en el contexto de su pueblo pues su padre fue Alcalde de Huarochirí (Mejía Xesspe 1948; Carrión Cachot 1948a), sus condiciones económicas siempre fueron modestas. En muchos trabajos sobre la vida de Julio C. Tello se ha enfatizado la humildad de su familia, pero por otro lado no se ha profundizado el rol político de los Tello como autoridades de una pequeña población andina y sobre todo el impacto que esta situación debió generar en el futuro intelectual. Consideramos que esta es una esfera que deberá ser motivo de estudio en el futuro. Cabe considerar aquí, la influencia de su padre en su posterior obra académica. Toribio
Mejía Xesspe (1948) ha remarcado la importancia y el esfuerzo que puso el padre de Tello en la construcción de un sistema hidráulico para mejorar las condiciones agrícolas para los pobladores de Huarochirí. Es interesante anotar que posteriormente Tello dedique su tiempo a analizar y hacer una descripción completa del sistema de irrigación prehispánico de Cumbemayo en el actual departamento de Cajamarca. Aunque este documento no ha sido publicado aún, el "Archivo Tello" de la UNMSM contiene 18 fólderes con mas de 150 páginas escritas sobre este sistema de irrigación, así como numerosos dibujos, mapas, etc. (Valcárcel Esparza 1966: 23-24). Este es el único trabajo que se le conoce a Tello sobre hidraúlica, pues a pesar de haber recorrido la costa norte peruana, donde estas obras de ingeniería abundan, no se tomó el tiempo de publicar informes o investigaciones al respecto ${ }^{2}$. Esto significa que pudo haber dado un valor subjetivo al sistema hidráulico ubicado en la sierra en vez de los ubicados en la costa. Del mismo modo, ya que este sistema fue en opinión de Tello construido en tiempos Chavín, adquirió una connotación especial. En resumen, esta puede ser una de las tantas líneas de evidencia en las cuales se puede ver la influencia que tuvo su pueblo de procedencia y más aún la figura paterna en sus vagos recuerdos de infancia ${ }^{3}$. Por otro lado, Luis E. Valcárcel tuvo una vida mas acomodada. Su familia se mudó cuando era aún muy niño de Moquegua hacia Cuzco. En esta ciudad, su padre estableció un próspero comercio que le permitió a la familia frecuentar las reuniones de la aristocracia cuzqueña (Matos et al. 1981: 95). El padre de Valcárcel se destacaba

2 Desconocemos si en las descripciones hechas sobre la arqueología de los valles de Lambayeque, Jequetepeque y Chicama, del Archivo Tello custodiado por la UNMSM en Lima existan notas, manuscritos o descripciones sobre los sistemas de irrigación de esta zona. Según la lista publicada por C. Daniel Valcárcel (1966) no parecería que el sabio se haya detenido ha hacer una descripción similar a la de Cumbemayo.

3 Particularmente en el caso de Tello, esto se puede apreciar desde que optó por estudiar los cráneos prehispánicos debido al fortuito hallazgo en una revista sobre unos cráneos que su familia recolectó para el Dr. Muñiz (Daggett 2009; Carrión Cachot 1948a; Lothrop 1948). 
por apoyar con alimentos a los indigentes del Cuzco, ofreciéndoles raciones de alimentos todos los sábados. Estas escenas quedaron guardadas en la memoria de Luis E. Valcárcel así como su proximidad filial con el personal doméstico de su residencia (Matos et al. 1981: 123), lo cual fue configurando en su mente la existencia de dos grupos antagónicos en su medio.

Mientras que por un lado se conservan algunas anécdotas del niño huarochirano jugando entre animales y pastos de su comunidad (Ponce Sanchez 1957), el niño afincado en el Cuzco creció en un mundo absorbido por el catolicismo (por influencia materna) que a la larga no llegará a asimilar y en los actos cívicos o los almuerzos en las elegantes y ostentosas haciendas de las afueras del Cuzco. Mientras uno recorrerá con su padre y hermanos los parajes con restos de ocupaciones prehispánicas desperdigadas en los campos y quebradas, el otro crecerá en la rigurosidad esquemática de una antigua ciudad imperial ahogada por la soberbia y belleza de la arquitectura incaica y virreinal. Este mundo tan distinto, a primera impresión, parece gestar una personalidad idónea en cada uno de nuestros intelectuales. Tello recorrerá el Perú en muchas expediciones, avocándose principalmente al entendimiento de su medio y a los grandes grupos étnicos que conformaron la secuencia histórica del Perú, basado únicamente en la evidencia arqueológica disponible (Tello 1929) mientras que Valcárcel tratará de explicar el pasado en base al testimonio de aquellos que conquistaron un mundo subyacente a los que impusieron su cultura y al uso de la etnología como medio para confirmar el continuum cultural entre el pasado y el presente (Valcárcel 1946a). Sin embargo, ambos reconocen que existe un elemento vivo, un segmento de la población que se cree la heredera directa de las antiguas sociedades prehispánicas las cuales aún están bajo 500 años de opresión. Tanto Tello como Valcárcel van a reconocer que los indios son un grupo biológicamente descendiente de los antiguos peruanos pero al mismo tiempo que tienen un aletargamiento en su comportamiento tras centurias de opresión y explotación, debido a que están concentrados en sobrevivir antes que desarrollar sus capaci- dades en el arte, literatura y tecnología (Carrión Cachot 1948b: 198; Matos et al. 1981: 217). La diferencia sustancial entre ambas propuestas es que para Valcárcel había un mestizaje biológico pero no cultural (Matos et al. 1981: 328), mientras que Tello creía en la unidad del poblador andino, sean indios o mestizos. Esta paradoja gestada en sus propias experiencias desde la infancia, va a marcar la tendencia indigenista peruana.

\section{La confrontación de Julio C. Tello y \\ Luis E. VALCÁRCEL: COYUNTURA, POLÍTICA Y OPORTUNISMO EN LOS PRIMEROS AÑOS DE LA arqueología nacional del Perú}

Entre 1895 y 1919 se inicia el periodo político conocido como la "República Aristocrática". En este corto periodo de 24 años, nueve presidentes se ponen al frente del país, lo cual evidenció el frágil poder del estado. Fue una época en la que la oligarquía limeña se disputó el poder y control estatal, dejando de lado al resto del país. Durante este periodo se generará el marcado centralismo capitalino que hasta la fecha es uno de los males que adolece el Perú. A pesar que los presidentes de este periodo intentaron respetar el status quo, siempre maniobraron para jugar a favor de los grupos aristocráticos y sus intereses. Esta situación generó lo que Huiza ha denominado el país "legal” y el país "real" (Huiza 2004: 182). El alejamiento del estado del resto del país generaría a la larga el dominio de los grupos terratenientes del interior, lo cual fue generando (entre otras razones) las condiciones para el posterior movimiento indigenista. A falta de una ideología directriz, el funcionamiento del estado oligárquico se apoyó más en la violencia que en el consenso (Burga y Flores-Galindo 1984: 83, citado en Huiza 2004: 183). Las divisiones al interior del partido civilista motivó la creación de dos grupos irreconciliables que son los que van a disputarse el poder durante los años en que Tello y Valcárcel estarán en escena. Coincidentemente, ambos pertenecieron a una facción política antagónica por lo que durante una etapa de sus vidas, tendrán una confrontación política e intelectual muy acentuada. 
En 1919 se da una situación política muy peculiar en el país. El pueblo estaba cansado del "civilismo oligárquico e impopular". Por ello, no hubo obstáculo alguno para que Augusto B. Leguía se imponga en las elecciones presidenciales de ese año (Palacios 2004: 209). Durante su gobierno, Leguía generó las condiciones legales necesarias para no depender de sus adversarios políticos, cambiando el sistema del Congreso de la República y dictando la nueva constitución política del país (Palacios 2004: 211). A pesar que Leguía tuvo una marcada tendencia de apoyo hacia la cultura y como parte de ello adoptó a Julio C. Tello (Mesía 2006), sus políticas dictatoriales le permitieron estar en el poder por espacio de 11 años, pero luego fue desterrado de su cargo por la revolución encabezada por Luis M. Sanchéz Cerro quien además tenía simpatía por Luis E. Valcárcel.

Nadie puede negar el rol protagónico que Tello y Valcárcel jugaron en la conformación de las ciencias sociales en el Perú. Cada uno desde su punto de vista y sus contribuciones forjaron las bases de la arqueología y antropología. Siempre se ha mencionado esto último, pero nunca se ha presentado los detalles de la vida que llevaron ambos investigadores durante su etapa de interacción. En la literatura actual se ha mencionado las confrontaciones directas entre ambos pero no se ha pretendido explicar las situaciones (Daggett 2009; Murra 2009). Las siguientes páginas tratan de llenar el vacío existente sobre las luchas que enfrentaron a Tello y Valcárcel.

Tras una campaña de desprestigio que se suscita principalmente en el diario Limeño "Libertad" dirigido por Francisco Loayza contra Julio C. Tello, se genera el ambiente necesario para poner a la opinión pública la integridad profesional y por ende la continuidad de Tello frente a la dirección del Museo de Arqueología Peruana, cargo que tenía desde 1913 (Daggett 1996). Tras la caída de Leguía, muchos de sus simpatizantes y militantes fueron perseguidos y Tello, consagrado militante del partido de gobierno fue rápidamente sustituido por Luis E. Valcárcel quien había sido originalmente llamado para asumir la dirección del Museo Bolivariano (Daggett 2009: 32; Tello y Mejía
Xesspe 1967: 172; Matos et al. 1981: 262). El mismo Valcárcel reconoce que fueron momentos difíciles para tomar una decisión, pues Tello era "la persona idónea" para el cargo. Por otro lado, asegura que se le presentaba una situación inmejorable para desarrollar varios proyectos que tenía en mente (Matos et al. 1981: 262-263). Es así que el 30 de septiembre de 1930 Luis E. Valcárcel asume la dirección de dicha institución y rápidamente genera las condiciones necesarias para agrupar todos los museos de la ciudad de Lima en una sola entidad cultural denominada "Museo Nacional”. Así, Tello y sus discípulos quedan despojados de su centro de trabajo e investigaciones. La situación empeoraría dos años mas tarde al cerrarse indefinidamente la Universidad Nacional Mayor de San Marcos, lo que dejó prácticamente sin un ingreso económico a Tello (Daggett 1994: 4). Esta situación se vería parcialmente aliviada para Tello cuando asume el dictado de una modesta cátedra por invitación de Riva Agüero en la Universidad Católica de Lima.

Valcárcel fue en la década de 1920 un marcado opositor al gobierno de Leguía (Matos et al. 1981: 226). Durante ese peiodo había establecido buenas relaciones con una serie de cuzqueños que luego tendrían posiciones claves en el gobierno como José Ángel Escalante o Francisco Tamayo Pacheco. Fue precisamente este último quien lo recomendó para que asuma la dirección del Museo Bolivariano en 1930. Este mismo personaje lo mandó llamar cuando el general Gustavo Jiménez tomó el control del ejército a la salida de Sánchez Cerro. Fueron ellos quienes propusieron a Valcárcel influenciar en David Samanez Ocampo para que gobierne el Perú mientras se organizaban las elecciones presidenciales. Samanez Ocampo fue un antileguiista con quien Valcárcel tuvo mucho acercamiento, al punto que Samanez Ocampo fue padrino de su primera hija. Cuando Samanez Ocampo se convierte en presidente del Perú, Valcárcel se vuelve uno de sus mas cercanos asesores, motivo por el cual, el poder que debió tener en las esferas políticas debió ser muy fuerte (Matos et al. 1981: 272). Con esta plataforma política es fácil entender el poder que tuvo Valcárcel durante el periodo de tiempo entre 1930-1948 que va a manifes- 
tarse plenamente cuando es elegido Ministro de Educación en 1945. Resulta interesante que es ese mismo año cuando se le reasigna a Tello su puesto de director del museo, es decir cuando Valcárcel deja el puesto vacante para ocupar su oficina ministerial. Durante este periodo Valcárcel va a conseguir fondos para publicar la Revista del Museo Nacional, para unificar el museo en una sola entidad, para crear nuevos institutos y dependencias de cultura así como adquirir mas prestigio internacional. Por ejemplo en 1946, a un año de estar ejerciendo como ministro, va a escribir en el famoso Handbook of South American Indians (Valcárcel 1946b, 1946c, 1946d). Del mismo modo se le va a mencionar en casi todos los libros, boletines o artículos publicados por investigadores extranjeros, quienes reconocían su autoridad y control de las ciencias sociales en el Perú (ver por ejemplo: Ford and Willey 1948: 6; Willey and Corbett 1950: viii; Bennet 1939: 3; Collier 1955: 9).

\section{Las confrontaciones de Julio C. Tello con EMILIO Gutierrez de Quintanilla}

Antes que Valcárcel apareciera en el escenario de la cultura limeña, Tello había tenido una serie de enfrentamientos desde 1913 con Emilio Gutierrez de Quintanilla. Este era un historiador de trayectoria en el Perú y se caracterizaba por sus discursos hispanófilos y republicanos. Cuando en 1912 asume la dirección del Museo de Historia Nacional el cual había sido fundado por Max Uhle en 1906 a iniciativa del entonces presidente de la República José Pardo (Daggett 2009: 11; Tello y Mejía Xesspe 1967: 60), dada su especialidad, le da más énfasis a las salas dedicadas al periodo virreinal y republicano. Tras una petición oficial de Julio C. Tello al gobierno de Guillermo Billinghurst para la creación de la sección de antropología en el Museo de Historia Nacional así como la conducción de la misma, ésta es aprobada, ingresando a laborar en dicha institución como encargado del área de arqueología y antropología. Debido a su formación antropológica, Tello propone un cambio estructural en el mes de julio del mismo año (Tello 1913). Esta propuesta, en la que se enfatizaba la exhibi- ción de componentes prehispánicos, motivó una profunda y contrariada reacción del historiador Gutierrez de Quintanilla. Tal fue el desenfado, que llevó las cosas al plano personal. La plena manifestación del repudio de Gutierrez de Quintanilla a Tello se materializó en un libro titulado "El Manco Cápac de la arqueología peruana. Julio C. Tello (Sr. De Huarochirí)” editado en 1922 , donde descarga toda su frustración, acusaciones infundadas y sus puntos de vista en contra de las políticas y orientaciones académicas de Tello. En una ocasión, Valcárcel comentó que entre Tello y Gutierrez de Quintanilla se llamaban "El Indio" y "El Español" (Matos et al. 1981: 262). Es interesante leer algunas secciones del mencionado libro donde el autor parece relatar algunos hechos con cierta veracidad. En un oficio dirigido al director de General de Instrucción fechada el 28 de julio de 1913 y publicada en el mencionado libro (Gutierrez de Quintanilla 1922: 13-29), se indica que Tello se refirió públicamente (en un panfleto) sobre la situación del museo: "... acumulación congestiva de objetos miscelánicos desplegados extravagantemente, a impulso de un afán ingenuo de dispersar conjuntos que ilustran, para formar una exposición caricaturesca, contra la cual claman los amantes a la estética..." (op cit: 14). Gutierrez de Quintanilla se queja luego que al publicar estas declaraciones, Tello no tuvo en consideración el poco presupuesto disponible, y sobre todo las condiciones en las que sus antecesores recibieron el museo. Gutierrez de Quintanilla detalla que junto a su personal estuvo trabajando por espacio de 15 meses en el fotografiado, catalogación, y limpieza de las colecciones del abandonado depósito así como el establecimiento de servicios de agua, desagüe y alumbrado. Indica además que hasta diciembre de 1912, el museo no tuvo una partida presupuestal y que solo vivía de donaciones y algún dinero depositado eventualmente por el gobierno, lo cual imposibilitó hacer más obras (Gutierrez de Quintanilla 1922: 14-15). Sin embargo, el argumento principal de Tello en su famoso documento "Presente y Futuro del Museo Nacional” (Tello y Mejía Xesspe 1967: 85-95), fue que se había desplazado las colecciones prehispánicas fundadas y ordenadas por Uhle. Vea- 
mos la versión de Gutierrez de Quintanilla al respecto:"Así pues, va de suyo que no puse, ni pude poner mano a las Colecciones arqueológicas, cuya presentación al público conservé inalterable. Lo único que a este respecto hice, fue trasladar a la cuarta sala, el retablo mixturado de Acarí que Mr. Uhle arregló en la segunda sala, y guardar dentro de la vitrina Nro. 29 los trescientos y tantos huacos que en aquel retablo permanecieron al alcance de la rapacidad, hasta la fecha de mi nombramiento. De ella extraje, con tal objeto, las varias momias procedentes de la Rinconada de Ate, cuyo nauseabundo e insoportable hedor infestaba la cuarta sala, y se desprendía de núcleos putrefactos. Con muy poca experiencia, y contra el testimonio de los sentidos, afirma el joven arqueólogo que el hedor debió ser imaginario, porque las momias están acépticas al cabo de algunos siglos. El olfato vence en este caso a la ciencia" (Gutierrez de Quintanilla 1922: 15). Otro argumento de Gutierrez de Quintanilla era que la estructura misma del edificio que albergaba la exposición del museo (los altos del Palacio de la Exposición) era totalmente inadecuada, lo cual conformaba un único y gran salón de exhibición, donde además todas las paredes perimétricas presentaban ventanales, dejando muy poco espacio libre para colgar o ubicar objetos. Asimismo, recalca que el problema de la iluminación solar directa durante los meses de verano, afectaba los objetos arqueológicos y que las telas que cubrían dichos ventanales no fueron colocadas por su mandato, sino por Uhle para proteger las colecciones (Gutierrez de Quintanilla 1922: 16). Asimismo, la queja directa de este personaje radicaba en que no se podía reducir toda la historia del Perú a los aportes que la arqueología podía dar "...pero en cambio imprime un panfleto en que propone a Ud. empequeñecer y apagar la historia colonial y del Perú independiente, así como las manifestaciones de arte nacional, aplastando la una y las otra bajo el peso somatológico y folklórico de un ridículo imperialismo ejercido por las momias, a influjo de un amauta exclusivista que se digna admitir la historia patria y el arte nacional entre los menudos e insignificantes tipos de su servidumbre. Seguramente, no es tal monstruosidad lo que conviene al país; pero está claro que es lo que conviene al amaute de la arqueología" (Gutierrez de Quintanilla 1922: 19). Finalmente, el historiador se queja acerca de algunas medidas tomadas por Tello en los primeros meses en los que estuvo a cargo de la sección arqueológica del museo. Una de ellas fue la cancelación del Ateneo de Lima (que funcionaba en el local del museo), el desalojo del Instituto Histórico así como la transformación en depósitos para objetos arqueológicos de un par de ambientes que se venían usando en las actividades de la academia "Estímulo de Arte Nacional" donde se daban clases de dibujo natural, pintura, escultura y música (Gutierrez de Quintanilla 1922: 23, 35). Esta última acción fue motivo de reclamos por parte de los estudiantes de dicho centro, cuyo documento y firmas también fueron publicadas por Gutierrez de Quintanilla en su libro contra Tello. De esta situación se puede proponer una serie de situaciones cuyunturales. La primera conclusión que ha sido discutida por algunos investigadores es que el problema central fueron los celos de Gutierrez de Quintanilla al ver que su autoridad se iba viendo desplazada por la incorporación de un experto, graduado de la Universidad de Harvard, en la institución en la cual el mismo había sido recientemente nombrado (no mas de dos años antes). También se ha evaluado la poca importancia que se le había dado a la arqueología hasta entonces, redundado en un enfoque histórico de la colonia y república. Esto sin embargo, no es del todo cierto debido a que a inicios del siglo XX, el presidente peruano José Pardo había convocado al arqueólogo mas renombrado del medio para crear el Museo de Historia Nacional (Tello y Mejía Xesspe 1967; Rowe 1954). Max Uhle inició sus labores en 1906 y se dedicó hasta su salida en 1912 a acumular colecciones en base a compras y proyectos de investigaciones arqueológicas que el mismo conducía (Rowe 1954; Kaulicke 1998). Cuando se inauguró el museo, éste tenía dos grandes secciones de exhibición: la sección arqueológica y por otro lado la sección de Tribus Salvajes y de la Colonia y de la República (Anónimo 1906:403). La primera recayó en Uhle, mientras que la segunda sección se puso a cargo de José Augusto de Izcue. De acuerdo a la pri- 
mera disposición del museo, el vestíbulo tenía un espacio destinado a ubicar el monolito de Chavín (Estela Raimondi) junto con otras piezas líticas de arte prehispánico. Es interesante que se haya decidido recibir a los visitantes del museo con la estela Chavín, que, a parte de su conspicua belleza e importancia arqueológica, constituía un bastión de la peruanidad, como un mudo testigo sobreviviente de las atrocidades cometidas por el ejército chileno durante la ocupación de Lima. De acuerdo a la descripción de la historia de los museos del Perú publicada por Tello y Mejía Xesspe (1967), mencionan que dicha pieza de arte ya había sido embalada por los chilenos y se había removido del museo. Por alguna razón fue abandonada y posteriormente fue encontrada por José Toribio Polo cerca de lo que hoy es el palacio de gobierno a espaldas de la Plaza Mayor de Lima (Tello y Mejía Xesspe 1967: 50). En el vestíbulo del piso superior, se ubicaba una suerte de sala etnográfica donde se pretendía exhibir algunas costumbres y uso de tecnologías que provenían de periodos prehispánicos y que aún se podían apreciar en algunos pueblos andinos. Seguidamente, la primera sala era la de Tribus Salvajes, donde se mostraba objetos de los grupos Aguarunas. La sección arqueológica se iniciaba con una exhibición de objetos de la costa norte, principalmente Proto Chimú (Moche) y Chimú. Sin embargo, la parte central de dicha sección eran lo materiales recuperados por Uhle en excavaciones arqueológicas conducidas en el sitio de Cajamarquilla, ubicado cerca de la ciudad de Lima (Anónimo 1906: 404). Finalmente la sala de la Colonia y República poseía aparentemente más objetos debido a que se trataban de donaciones que muchas familias hicieron para dicha exhibición. Se debe considerar que era una época donde se daba valor a piezas arqueológicas excepcionales, mientras que el resto eran descartadas o no se les consideraba apropiadas para una exhibición museográfica. Por tal razón, Uhle debió pasar serios aprietos para conseguir obras de calidad (de acuerdo a los cánones de la época) para ex- hibir en su museo ${ }^{4}$. En este sentido, llama la atención que parte de los objetos mas valiosos de la sala de la Colonia y República eran la espada de Francisco Bolognesi, el catre de campaña de Sucre, un fragmento del monitor Huáscar, la gorra y chatarrera de Miguel Grau, etc. Todos estos objetos eran "reliquias" de los héroes de la guerra del Pacífico (1879-1884) y la independencia (Anónimo 1906: 404). Esto indica el marcado nacionalismo que a través de la exhibición se pretendía remarcar a los visitantes. No debemos olvidar que el Perú se había encontrado en una guerra donde aparte de la pérdida de territorios, endeudamiento internacional y el corte al crédito y actividades económicas con el extranjero, había causado una seria crisis en todos los ámbitos sociales, generando un profundo sentimiento de frustración y baja autoestima (Basadre 1946). Por esta razón, la idea de iniciar la exhibición del Museo de Historia Nacional con la Estela Raimondi, uno de los pocos "sobrevivientes" al saqueo efectuado por los chilenos en el antiguo museo de Lima, era un claro mensaje de patriotismo y reconstrucción nacional que en esa época se venía enfatizado. La sección de Colonia y República tenía la intención de mostrar el pasado hispano del Perú, pero también remarcar y generar en la conciencia colectiva peruana los personajes (y las obras) de a) la Independencia del país y b) los héroes de la guerra con Chile, donde a pesar de haber sido derrotados, se utilizaron dichos íconos para formar los valores y sentimientos patrióticos de las nuevas generaciones. Esto se puede evidenciar actualmente en las fechas cívicas nacionales y en la educación escolar, donde todos los héroes de dicha guerra son emulados como ejemplos a seguir por su servicio al país (véase la "caballerosidad y generosidad" de Miguel Grau, el "coraje y valentía" de Ugarte, el "patriotismo" de Bolog-

4 No se debe olvidar que años antes, el mismo había mandado cientos de especies a los museos de la Universidad de Berkeley en California (Rowe 1954). Es interesante anotar que una carta a Putnam, Uhle indica que se trataba del último envío de piezas arqueológicas, pues en adelante solo se harían exportaciones de bienes arqueológicos con autorización del museo y el estado, siempre y cuando existan réplicas en las colecciones del país. (Rowe 1954: 111) 
nesi, "la astucia" de Cáceres, etc.). Por otro lado, el hecho que se haya dedicado una sala etnográfica donde se enfaticen ciertas continuidades tecnológicas y tradicionales prehispánicas en las poblaciones actuales de los andes junto a la sección arqueológica, indica el incipiente interés por la rama etnológica de la antropología. La sub sección de las tribus salvajes de la región del Marañón, debe haber correspondido a una tendencia modista de la época, en que varias exposiciones internacionales como el museo de New York o el museo de Berkeley o el British, exhibían las "rarezas" de las tribus de "salvajes" de las regiones que tenían bajo su dominio. Finalmente se fundó la "Revista Histórica", órgano destinado a publicar las investigaciones del $\mathrm{Mu}$ seo de Historia Nacional. El primer artículo publicado allí, fue de carácter arqueológico y fue escrito por Max Uhle, el cual lo tituló "Los Kjoekkenmöeddings del Perú”, el cual fue básicamente una compilación de los trabajos y sitios con evidencia de explotación y producción marina en las costas peruanas, debatiendo su antigüedad y naturaleza. Este trabajo estuvo fuertemente influenciado por sus investigaciones en los conchales de la costa oeste de Estados Unidos, lo cual constituyó uno de los últimos trabajos arqueológicos que realizó en este país (Rowe 1954; Kaulicke 1998). Si bien es cierto la tendencia de la Revista Histórica fue el estudio de fuentes documentales, se fue notando un mayor incremento de publicaciones de carácter arqueológico principalmente sobre descripciones y estudios de colecciones en los siguientes números. Se debe tener en cuenta que en esa época no existía la carrera arqueológica o antropológica en el Perú, y los que la habían estudiado eran especialistas extranjeros que visitaban el país esporádicamente (Squier, Middendorf, Reiss y Stubel, etc.). De otro lado los estudios históricos tenían una larga tradición desde el tiempo de los cronistas durante el virreinato.

Esta situación indica que en los escasos 6 años desde la inauguración del Museo de Historia Nacional (1906-1912), se había conseguido el avance de establecer una sala de exposición arqueológica a iniciativa del propio gobierno peruano. Para ese entonces, no se tenía una clara idea del pasado prehispánico peruano y Uhle se encontraba en pleno proceso de estudio, aunque con algunas ideas equivocadas respecto al origen de las poblaciones en los andes. No obstante, había logrado establecer la primera secuencia cronológica en base a sus excavaciones estratigráficas en el sitio Huacas de Moche y en Pachacamac, razón por la cual fue considerado por John Rowe como el "Padre de la Arqueología Peruana" entre otros méritos. Estos pocos avances, fueron de una u otra manera plasmados en la sección del museo que Uhle dirigía, y por tal razón, no se tenía más conocimiento que el mostrado bajo los esquemas teóricos del investigador alemán. En este contexto, resultan ciertas las apreciaciones de Gutierrez de Quintanilla respecto a la situación de la sección arqueológica, la cual al no ser de su especialidad, optó por dejarla tal cual fue ambientada por Uhle. Se debe entender que Gutierrez de Quintanilla era un historiador y su formación en esa época no abarcaba el estudio prehispánico del Perú, lo cual se evidenció por la falta de interés que le dio a la sección fundada por Uhle durante los 15 meses de dirección que tuvo en el museo. Bajo esta perspectiva, no creemos que haya existido una "relegación" de las colecciones arqueológicas y por ende del pasado prehispánico peruano, sino que a) el museo no contaba aún con colecciones apropiadas (en el contexto de la época), b) no se había establecido una secuencia cronológica coherente ${ }^{5}$, c) se consideraba el origen de las altas culturas peruanas como el resultado de la influencia centro americana y d) Uhle no había mostrado interés en renovar las exhibiciones, debido entre otras cosas, a la falta de presupuesto. En este sentido no encaja del todo el reclamo de Tello sobre la situación que se presentaba en el Museo de Historia Nacional. En 1912, Tello contaba con 32 años y se sentía, con justa razón, como la autoridad académica en el país para iniciar los estudios arqueológicos de una manera sistematizada

5 Debe considerarse que los trabajos de Uhle van a ser sintetizados y ordenados posteriormente por Alfred Kroeber y sus estudiantes (Kroeber 1924, 1925, 1926), por lo tanto los aportes que hubiera aportado Uhle, estaban lejos de concretarse al no haber estudiado en detalle o mejor dicho no haber publicado sus conclusiones y perspectivas sobre el material acumulado. 
y ordenada. Creemos que el ímpetu de enfatizar la sección arqueológica y antropológica del museo se debía a las siguientes causas: a) reorganizar e implementar la muestra disponible del museo en base a nuevas investigaciones, reconociendo y excavando en los sitios arqueológicos del país; b) cuestionar los planteamientos emitidos por Uhle acerca del origen de las civilizaciones andinas; c) reivindicar su "raza" indígena, cambiando la orientación y el discurso ideológico del país desde una perspectiva histórica hacia una revaloración de las antiguas culturas prehispánicas y d) establecer para el mismo un campo de trabajo que le permita desarrollar sus investigaciones y proyectos, a la par que un ingreso económico para su sostenimiento. La ejecución de todos estos objetivos tenía la dura barrera de pelear contra dos factores que jugaban en su contra. Por un lado tenía la enraizada cultura del historicismo, fuertemente afincada en el Perú (y en realidad en todo Latinoamérica a inicios del siglo XX), que trataba de emular el proceso histórico reciente que había dado forma e identidad a las nuevas repúblicas independientes de esta parte del continente americano. El otro aspecto, eran los prejuicios y concepciones que se tenían en esa época sobre el componente poblacional indígena y mestizo en la costa peruana y especialmente en Lima. Hacia finales del siglo XIX la población de Lima comenzó a incrementarse por la migración de pobladores procedentes de la sierra. Al mismo tiempo, se da la llamada "Revolución Demográfica” que afectó en general a América Latina y debió al mantenimiento y crecimiento de las tasas de natalidad mientras que las tasas de mortalidad descendieron sensiblemente (Deler 1975: 20). Este proceso había causado un severo incremento poblacional en las ciudades y especialmente en Lima. La mayor cantidad de los migrantes venían con la intención de buscar un trabajo pues las condiciones económicas al término de la era del Guano y posteriormente con la guerra del Pacífico, había ocasionado una crisis muy fuerte, por lo que muchas compañías y centros de trabajo cerraron puertas, motivando el aumento de la delincuencia, prostitución y miseria. Si bien es cierto que desde la colonia ya existían núcleos de barriadas en los alrededores de la ciudad de Lima, poco a poco el mismo centro de la ciudad se fue convirtiendo en espacio de residencia para los migrantes. Al mismo tiempo, esto fue motivado por los propietarios de los antiguos solares del centro histórico, quienes al no contar con recursos económicos producto de la crisis, se habían retirado a sus haciendas en las afueras de Lima, convirtiendo sus propiedades del centro de la ciudad en pensiones y quintas, donde hasta el día de hoy viven centenares de familias en lo que el acervo popular denominó "el viejo callejón de un solo caño”. De esta manera Tello, que había sido parte de esa ola migrante que buscaba un futuro mejor a través del trabajo o el estudio en colegios y posteriormente en la universidad, entendía la problemática de ese componente poblacional, pero al mismo tiempo era conciente de los prejuicios raciales y denigrantes en esa época. Así, Emilio Gutierrez de Quintanilla, aristócrata e historiador, representaba un fuerte obstáculo, no solo en lo académico, sino en lo social. Bajo esta perspectiva, la evidencia sugiere que Tello debió actuar con rapidez, rudeza e inteligencia, para sacarse del camino a un personaje que de otro lado, lo hubiera condicionado y relegado al ser "racialmente y socialmente inferior a el”. Del mismo modo tenemos la sospecha que Gutierrez de Quintanilla pertenecía al rancio partido civilista, mientras que Tello llevaba la bandera de Leguía y la reforma social. Por esta razón, creemos que Tello actuó ante una situación en la que usando su novedosa y alta reputación como científico y tomando el estandarte de la importancia de la antropología y la arqueología para entender y revalorar nuestra historia, le permitiría sobreponerse a las ideas y perspectivas de Gutierrez de Quintanilla. Solo así lograría el objetivo de tener amplia libertad de estudiar el pasado prehispánico canalizando la mayor cantidad de fondos posibles para realizar investigaciones arqueológicas en los sitios dispersos a lo largo del Perú. Como el mismo mencionó en una oportunidad al ingresar por primera vez al Museo de Historia Nacional y revisar las colecciones, era conciente que no se conocía nada acerca de su procedencia y de su ubicación cronológica, por lo que dedicó sus esfuerzos a recorrer y 
excavar los asentamientos prehispánicos desperdigados en las múltiples regiones geográficas del país para iniciar un ordenamiento sistemático y cronológico de dichos objetos, que a la larga le permitirían entender el desarrollo cultural de dichas civilizaciones (Carrión Cachot 1948a: 11). De esta manera, creemos que el poco interés que mostraba Tello en los periodos Colonial y Republicano fue el resultado de una estrategia para generar una corriente de interés hacia el periodo prehispánico y no solamente como la veta para la exhibición de curiosidades o como fuente de enriquecimiento a través de la venta ilegal de estos objetos. Al mismo tiempo era una negación del enfoque civilista de la cultura en el país, donde la elite erudita encarnada en la Colonia y la República, estaban llamadas a salvar y dirigir la patria. Tello adopta la ideología de Leguía, en la que un nuevo peruano, el mestizo y el indio debían reivindicar el viejo imperio incaico. Probablemente el mismo Leguía se veía como un Inca al tener el poder absoluto del gobierno. Otro factor es que el creciente componente social "mestizo e indio" de la capital no se identificaba plenamente con el pasado Colonial y Republicano del país, debido a las marcadas tendencias sociales de la época, las cuales se arrastraban desde la conquista. Tello, al ser parte de este grupo comprendió que la mejor manera era reedificar una nueva conciencia nacional a través de la revaloración del pasado prehispánico pues allí estaban las raíces de la alta cultura (Burger 2009). Al asociar estas altas culturas con el componente poblacional indio y mestizo podía crear un doble efecto. Por un lado, tenía la idea de proveer un pasado y una historia a ese componente poblacional y por el otro desarrollar la arqueología y la antropología como los únicos medios para descubrir, describir, estudiar y analizar ese pasado. Por lo tanto, un país como el Perú, no podía prescindir de estas disciplinas para crear su historia nacional. Bajo su perspectiva era el momento propicio pues se estaba generando una tendencia hacia la revaloración de los pueblos andinos y su componente poblacional. En ese sentido, Tello mismo representaba la reivindicación de su raza y la muestra que con las condiciones necesarias, su gente era capaz de lograr grandes obras. Probablemente por esta razón, Tello creía que los indios peruanos estaban en un estado de "aletargamiento" producto de la total inversión de su energía y vitalidad en actividades de subsistencia (Carrion Cachot 1948b: 9).

Los enfrentamientos con Gutierrez de Quintanilla llegaron al extremo que el gobierno decide clausurar por un tiempo el Museo de Historia Nacional hasta su reapertura en diciembre de 1913 cuando crea el Museo de Arqueología y Antropología con Tello como director. Las acciones subsecuentes indican que Tello, a pesar de la inestabilidad política del país, recibió apoyo tanto del gobierno peruano como internacional para realizar más de 10 expediciones científicas a diversas regiones del país, donde tuvo la oportunidad de familiarizarse con los sitios, su entorno y sus colecciones. Creemos que el lapso de tiempo entre 1912 y 1917 fue una época en la que Tello tiene la capacidad de aprender y conocer mucho sobre los sitios y materiales arqueológicos del país, lo cual le dio fama entre los arqueólogos norteamericanos que nunca dejaron de reconocer el amplio conocimiento que éste tuvo (Willey 1988: 183) y que el mismo Tello reconoce al indicar que "... en mi trato con los profesores norteamericanos aprendí relativamente poco de la ciencia de mi predilección..." (Tello 1942: 485). Es decir, que si bien es cierto recibió una sólida formación académica en antropología, en esa época la academia norteamericana no contaba con estudios comparativos ni colecciones suficientes para educar a sus alumnos en los temas relacionados a los sitios y objetos arqueológicos de los andes. Se debe entender en este sentido que la arqueología andina era una ciencia en formación y es el mismo Tello y por la misma época Uhle los que van a dar impulso a estos estudios.

En conclusión, tras haber ganado la primacía y el favor del gobierno al ser reconocido oficialmente como máxima autoridad para los estudios arqueológicos en el país y dada la importancia y promoción que Tello le dio a la arqueología a partir de sus exploraciones e investigaciones, es plausible argumentar que desplazó a Gutierrez de Quintanilla a un segundo plano. 
Sin embargo esto no exceptuó que los enfrentamientos continúen casi 10 años después, en que se publica el famoso folleto del historiador en contra de Tello. Los años comprendidos entre 1923 hasta marzo de 1930, fueron de una aparente paz entre ambos académicos. No obstante, nuevos cambios vendrían en el ambiente político del Perú. La evidencia sugiere que Gutierrez de Quintanilla esperó pacientemente hasta que se dieran las condiciones necesarias para cobrar su revancha. Y si que lo hizo.

\section{El Fin del OnCenio de Leguía, LA OPORTUNIDAD DE VALCÁRCEL Y SU CONFRONTACIÓN CON TELLO}

El joven cuzqueño Luis E. Valcárcel, había tenido una activa participación en la huelga universitaria del Cuzco de 1909, la cual concluyó en la feliz contratación de Alberto Giesecke como rector de la Universidad del Cuzco. Posteriormente Valcárcel reconocería que Giesecke fue el gran artífice y maestro de los intelectuales cuzqueños de su generación (Matos et al. 1981: 140). A raíz de estos eventos, muchos de los jóvenes que habían estado envueltos en la huelga, establecieron lazos de solidaridad mediante correspondencia con algunos de los más renombrados pensadores de la capital limeña. José de la Riva Agüero fue uno de ellos y cuando éste realiza su visita a Cuzco en 1912, Luis E. Valcárcel (con quien se conocía por correspondencia debido a la situación descrita) se encarga de hacerle una visita personalizada por todos los atractivos de la zona. Del mismo modo le ofrece una cena de honor en su residencia (Matos et al. 1981: 158). Esta situación fue inmejorable para Valcárcel, pues no solo estableció un buen contacto, sino que a la larga esta relación le permitió tener un abierto acercamiento con las altas esferas de poder en Lima. Creemos que es aquí donde Valcárcel va a iniciar una serie de actos políticamente acertados, que concluirán construyendo la figura arquetípica del forjador de la institucionalización de la cultura en el Perú. Al poco tiempo de la visita de Riva Agüero al Cuzco, Valcárcel y otros jóvenes fueron comisionados para asistir al III Congreso Panamericano de Estudiantes de Lima. Como era de esperar, Riva Agüero ofrece su propia residencia como hospedaje al joven cuzqueño, al igual que cartas de presentación para familiares y amigos de su selecto círculo social. Además del congreso de estudiantes, uno de los objetivos políticos de la comisión del Cuzco en Lima era persuadir al presidente de la república para que sustituya al prefecto de esa ciudad andina, pues venía cometiendo una serie de actos de corrupción. Por esa época las elecciones presidenciales se perfilaban entre dos candidatos: Ántero Aspíllaga, representante de los intereses aristocráticos y Guillermo Billinghurst, que a pesar de pertenecer a la clase acomodada, tenía un discurso social orientado a la creciente masa obrera y gozaba del apoyo oficial de Augusto B. Leguía, por entonces presidente del Perú (primer gobierno). La astucia de esta comisión se centró en sacar una cita con Billinghurst, a quien detallaron posteriormente las intenciones del prefecto cuzqueño de apoyar parcializadamente la candidatura de su oponente. Junto a este argumento central, se logró establecer una reunión con el presidente Leguía para informarle los hechos y solicitarle el despido del prefecto. Días más tarde, la misión estaba cumplida y la autoridad cuzqueña fuera de su puesto (Matos et al. 1981: 162).

El éxito de Valcárcel durante su estadía en Lima se debió a las influencias y recomendaciones de Riva Agüero, las cuales le abrieron muchas puertas en la capital que de otro modo hubieran estado cerradas a un joven intelectual de provincia. Víctor Andrés Belaúnde, un pensador político de la época ampliamente reconocido por sus análisis y estudios del Perú al igual que Juan Bautista de Lavalle profesor y diplomático limeño, fueron por encargo expreso de Riva Agüero quienes introdujeron al joven cuzqueño en la vida social, política y cultural de Lima. Gracias a estas conexiones, Valcárcel conocerá a prominentes figuras del mundo académico, político y cultural, frecuentando sus residencias, centros de trabajo o los exclusivos locales donde se congregaban para las tertulias como el memorable Palais Concert del centro de Lima. Algunos de los mas relevantes fueron: Ricardo Palma, Javier Prado, Manuel Vicente Villarán, Leónidas Yerovi, Au- 
gusto Durand, Abelardo Gamarra "El Tunante" o Abraham Valdelomar "El Conde de Lemos". Estas conexiones dieron rápidamente sus frutos, llegando a publicar ese mismo año un artículo sobre el Inca Pachacutec en el diario "La Prensa". Del mismo modo Abelardo Gamarra le da la oportunidad de publicar varios artículos en el periódico "La Integridad". Estas publicaciones fueron las primeras que tuvo en Lima y fueron el inicio de una prolija producción literaria y académica. Valcárcel es conciente de la brillante oportunidad que se le presentaba y por ello se encargó de cultivar dichas relaciones con el paso de los años, lo cual le dieron un prematuro espacio como figura sobresaliente en las nuevas generaciones de intelectuales peruanos. Por esa misma época, Tello ya se había consolidado al obtener su grado de Master en Antropología en Harvard y se encontraba llevando cursos en Londres y atendiendo responsabilidades oficiales como representante del Perú en el XVIII Congreso de Americanistas de Londres, donde fue ampliamente aclamado (Dagget 2009: 14). En el plano político, Valcárcel había establecido conexiones con Billinghurst desde las entrevistas con Leguía, lo cual derivó en su afiliación al partido político de éste último donde trabajó tenazmente apoyando su campaña presidencial. Incluso llegó a dar discursos políticos ante masas de obreros en Lima (Matos et al. 1981: 168). Debido a su carácter y amena conversación, se ganó el aprecio del futuro presidente, siendo reiteradas veces invitado a su casa para compartir cenas. El decidido apoyo que le da a Billinghurst se debe a la especial capacidad de análisis y proyección que caracterizará a Valcárcel durante su carrera, teniendo una acertada decisión y orientación política, las cuales le fueron siempre favorables ${ }^{6} \mathrm{y}$ propicias para desarrollarse profesionalmente. Esto se puede confirmar cuando Billinghurst es elegido presidente de la repú-

6 Sin embargo es preciso indicar que el único error o falta de cálculo fue cuando se lanzó de diputado por la provincia de Chumbivilcas, donde tras el triunfo y estando en Lima para recibir sus credenciales, el presidente José Pardo recibió golpe de estado por parte de Augusto B. Leguía y por lo tanto se disolvió el nuevo congreso de la república. En una situación anecdótica, Valcárcel menciona que aún guardaba sus credenciales como diputado incluso 50 años después de los sucesos. blica, Valcárcel pasa rápidamente a ser Inspector Departamental de Educación en el Cuzco (Matos et al. 1981: 173). En ese puesto logra tener una visión y perspectiva general de la problemática de la educación en el país, sobre todo de la sierra. Años más tarde cuando sería elegido Ministro de Educación su experiencia como inspector departamental le servirá para abordar el problema de la educación del componente indígena del país. El profundo conocimiento de la enseñanza en el país, le permitirá publicar "La Educación del Campesino" en donde plantea los lineamientos para mejorar la educación del campesinado peruano (Valcárcel 1967).

Posteriormente, Valcárcel se desempeñará como abogado en el Cuzco, será redactor en periódicos locales e internacionales, como La Prensa de Argentina y también se desempeñará como catedrático de la Universidad del Cuzco (Matos et al. 1981: 205). Publicará algunos libros base del indigenismo como "La Cuestión Agraria del Cuzco" o "Del Ayllu al Imperio". Es decir, el periodo comprendido entre 1913 y 1930 no es oscuro ni infértil para Valcárcel, sino es un periodo de consolidación regional en el que se hace una figura intelectual muy prestigiosa y respetada en el Cuzco (José Luis Rénique, comunicación personal) (Tamayo 1980: 186). En 1930, tras una revolución en Arequipa, Luis M. Sanchez Cerro, derroca el gobierno de Augusto B. Leguía quien se había mantenido en el poder por espacio de 11 años. Debido a que Valcárcel era parte de los grupos políticos que apoyaban a Sanchez Cerro y al mismo tiempo anti-leguiísta, fue convocado para asumir la dirección del Museo Bolivariano en Lima. Al poco tiempo de su llegada a Lima el mismo presidente le anuncia su deseo de que se haga cargo del Museo de Arqueología Peruana, donde Tello venía laborando desde 1913 (Matos et al. 1981: 262). Es posible que algunas de sus conexiones en Lima hayan funcionado nuevamente para ser propuesto para dicho puesto. Creemos que la figura de Alberto Giesecke, quien desempeñaba un puesto alto en el gobierno y luego como miembro del cuerpo diplomático de la Embajada de Estados Unidos en el Perú, jugó un papel fundamental para su selección (José Luis Rénique y Enrique Mayer, 
comunicación personal). A pesar que Valcárcel reconocía la autoridad de Tello, acepta el puesto de director argumentando que tenía experiencia por haber fundado el Museo Arqueológico de la Universidad del Cuzco y porque quería desarrollar nuevas ideas sobre el manejo de los museos en el Perú. Evidentemente era la oportunidad que Valcárcel tenía para tener un predominio en la arqueología y la cultura del país. Al mismo tiempo, Valcárcel puede haber cobrado una vieja revancha política pues en la revolución de Leguía contra Pardo en 1919, pierde la oportunidad de ser diputado por Chumbivilcas (Matos et al. 1981: 203). Tello había sido diputado leguiísta por Huarochirí y al mismo tiempo ampliamente favorecido por el gobierno del oncenio (Mesía 2006). La clara tendencia leguiísta de Tello había jugado en su contra y una vez derrocado su líder político, se quedó sin el respaldo necesario para ejercer su carrera. Estos fueron momentos realmente tensos y desfavorables para Tello pues al poco tiempo se cerraría la Universidad $\mathrm{Na}$ cional Mayor de San Marcos, quedándose prácticamente sin un trabajo estable (Dagget 1996, 2009). Sin un empleo que le permita sostener sus gastos familiares e imposibilitado incluso de revisar sus materiales arqueológicos, Tello busca mecanismos para poder expresar sus ideas, inquietudes y críticas. En 1931 edita y publica el primer número de la revista "Wiracocha"(Fig. 2) en cuyo prólogo se puede notar su molestia y aberración por intelectuales como Valcárcel, quienes sin ser arqueólogos, y debido a coyunturas políticas estaban a la cabeza de las instituciones nacionales que velaban por el patrimonio prehispánico: "Los indianistas nacionales son en su mayoría, jurisconsultos, literatos, industriales, periodistas y conferencistas profesionales habituados a plantear y resolver con tanta facilidad como falta de fundamento, cualquier problema, educacional, religioso, político, económico, que por su carácter sensacional puede gratificar su personalidad o elevar su reputación intelectual(...) habituados a subordinar los hechos evidentes y la austeridad científica a la belleza del discurso o a las exigencias emocionales; y otras, por último, obedeciendo exclusivamente a los impulsos de su genial inspiración" (Tello 1931a:1). Como es evidente, Tello descarga una dura críti-

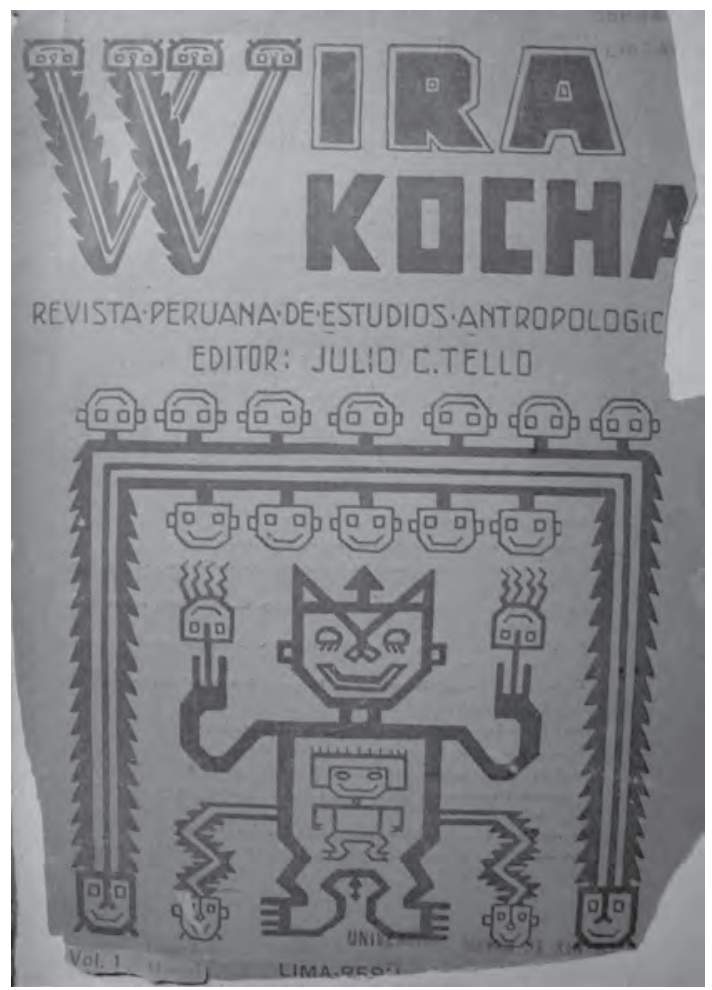

Figura 2: Portada de la revista "Wiracocha", fundada por Julio C. Tello.

ca contra los "jurisconsultos, literatos, periodistas". A nuestro juicio uno de los pocos abogados que había publicado libros sobre literatura andina ${ }^{7}$ y que regularmente escribía en los periódicos era Luis E. Valcárcel, por lo tanto la confrontación estaba abierta y era directa. Por otro lado, 40 años después Valcárcel argumentaba que “... la labor científica de Tello no podía truncarse, por lo que busqué la fórmula para mantenerlo en el museo" (Matos et al. 1981: 262). Esta aparente fórmula se da en la creación del Museo Nacional, proyecto en el cual Valcárcel trata de juntar todos los museos dispersos de la ciudad para crear un único ente organizativo y director, donde obviamente, el era el hombre orquesta. $\mathrm{Al}$ mismo tiempo crea los Institutos de Arte Peruano y los de Investigaciones Antropológicas e Históricas.

7 En 1931, Valcárcel publica las siguientes obras de corte literario: Mitología Peruana: Cuentos Solares; Irma: Cuentos y Leyendas Incas; Cuentos y Leyendas Incas. El Uturunku; El Matador de la Serpiente Alada. Cuentos y Leyendas Incas (Matos et al. 1981: 429-430). 
En estos últimos Tello estaría a cargo de la sección arqueológica y Gutierrez de Quintanilla en la parte histórica. Aquí es interesante señalar que Valcárcel era conciente del peso académico de Tello y del prestigio que éste tenía en el extranjero, especialmente en Estados Unidos que era donde el intelectual cuzqueño aspiraba. En ese sentido, la "fórmula" para mantener a Tello en el museo radicaba en que no podía deshacerse de el tan fácilmente. Políticamente Tello estaba arruinado, pero académicamente era prácticamente imposible borrar su nombre del medio. Por ello, una vez más, la genialidad compositora de Valcárcel juega para sus propios intereses y con la creación del Instituto de Investigaciones Antropológicas el cual “... debía funcionar como el laboratorio del Museo Nacional..." (Valcárcel 1981: 265) se convertía en el procesador de datos e investigaciones donde el mismo figuraba como el director y superior de toda la estructura de investigación arqueológica y antropológica en el país. En resumen, Tello se convertía como responsable de dicho instituto en el empleado subordinado, cuya misión era estudiar los objetos y restos arqueológicos para que luego sean interpretados de una forma más general por Valcárcel. Este punto se puede sustentar en los múltiples artículos escritos en libros, revistas y periódicos por Valcárcel, quien en vez de centrarse en un periodo en particular o un sitio, se dedica ha hacer los grandes resúmenes como "Arte Antiguo del Perú: cabezas humanas escultóricas", "Arte Antiguo del Perú. Estirpe Guerrera”, entre otros. Probablemente por esta razón Tello nunca publicó un solo artículo en la Revista del Museo Nacional, fundada por Valcárcel en 1932. De hecho la primera vez que aparece el nombre de Tello en la Revista del Museo Nacional fue una corta nota escrita en la sección "Necrología” por Valcárcel en 1947 tras su sensible fallecimiento. Es probable que Tello se haya dado cuenta de la estrategia de Valcárcel y por esta razón decide no publicar ninguno de sus trabajos. Al mismo tiempo, el carácter de Tello era muy fuerte y orgulloso (Ponce Sánchez 1957), por lo tanto es posible que haya concebido fuera de lugar presentar trabajos científicos en una revista que era editada por un abogado- escritor con clara tendencia a la historia. Otra opción es que Valcárcel nunca lo dejó publicar, lo que parecería poco probable pues si Tello lo hacía, hubiera incrementado el prestigio de esa edición y era precisamente aquello lo que Valcárcel anhelaba: sacar provecho de sus subalternos y mostrarse como el gran organizador de los estudios arqueológicos, antropológicos e históricos en el Perú.

En el prólogo del primer número de la Revista del Museo Nacional, Valcárcel reflexiona acertadamente sobre la necesidad de internacionalizar los trabajos arqueológicos en el Perú, como lo venía haciendo México o Guatemala. Menciona que los proyectos arqueológicos debían ser una mezcla de elementos nacionales con el apoyo logístico y económico del extranjero como las fundaciones Rockefeller o la Carnegie Institution. Refiere así mismo que el arqueólogo no es un simple excavador y coleccionista sino que conoce y reconoce al hombre y su medio (Valcárcel 1932: 4). Por otro lado indica que se deben restaurar los monumentos arqueológicos con el objeto de atraer turismo y generar identidad a partir de ello. Finalmente enfatiza que el estudio realizado por los investigadores extranjeros y nacionales debe enfocarse en que lo principal de sus expediciones debe ser el estudio de la raza y no la acumulación de colecciones. De una u otra manera, Valcárcel define la tendencia de la arqueología y antropología (así como más adelante la etnología y etnohistoria) del Perú donde los trabajos arqueológicos se vuelven cosmopolitas con apoyo del extranjero y en la restauración de monumentos arqueológicos por parte del gobierno central. Sin embargo falla en el deseo que la arqueología se acerque mas a reconocer las relaciones entre el hombre y su medio, así como el estudio de la raza y no solo las colecciones. La tendencia teórica y metodológica de la arqueología en ese tiempo era la Historia Cultural, y por lo tanto los arqueólogos estaban avocados al estudio de las secuencias culturales bajo un neo evolucionismo cultural donde el estudio de los artefactos permitía reconstruir las condiciones históricas y sociales en el pasado (Trigger 2007). 
Por otro lado, Emilio Gutierrez de Quintanilla estaba a cargo de la sección histórica del instituto. Su presencia debe relacionarse a las conexiones políticas que éste tenía y que Valcárcel debió conocer. A la caída de Leguía, Gutiérrez de Quintanilla encuentra finalmente el momento propicio, tanto en lo político como en lo situacional para vengarse de Tello. La campaña de desprestigio que se hizo en contra del futuro padre de la arqueología peruana tiene que haber sido conocida por Valcárcel, pues fue el argumento legal para poner en tela de juicio su continuidad como director del museo. La alianza Valcárcel-Gutierrez de Quintanilla, a pesar que el primero necesitaba de Tello, se confabuló en varias ocasiones para desprestigiar, fastidiar y hasta plagiar el trabajo del arqueólogo huarochirano. Tal es el punto de disputa que en una carta dirigida al director del diario "El Comercio" de Lima, Tello desmiente con evidencia y contundencia las falsas acusaciones que en su contra se habían efectuado (Daggett 1996). Uno de los pasajes más lamentables es que se le acusaba de tener palacios en el moderno barrio de Miraflores y Malecón de la Reserva así como tres casas en Inglaterra, vajilla de oro y plata y cuantiosas sumas de dinero en los bancos. Tello tiene que exhibir públicamente lo poco o nada que posee, y clama expresamente: "Creo que es poco lo que tiene un hombre que ha trabajado rudamente durante cerca de cuarenta años, dedicando todas sus energías al servicio público y a la realización del ideal de formar un gran Museo para el país..." (Tello 1930). Un caso directo en el que Tello y Valcárcel se enfrentan se da en julio de 1933. Tello consigue financiar una expedición a la costa norte del Perú, centrando su atención en las inmediaciones de Nepeña. Tras el descubrimiento de las ruinas de Punkurí y Cerro Blanco, las cuales da a conocer a través de la prensa (Anónimo 1933; Daggett 1987), Valcárcel (como autoridad máxima de la cultura y patrimonio del país) decide hacer una inspección sin previo aviso a Tello, quien no toma a bien la visita. Valcárcel fue acompañado por el Dr. Santiago Antúnez de Mayolo. En un artículo periodístico publicado el 5 de octubre de 1933,
"El Comercio" de Lima presenta nuevos avances sobre los trabajos en Nepeña, así como las opiniones vertidas por la comisión encabezada por Valcárcel y Antúnez de Mayolo respecto a los trabajos que Tello venía conduciendo. Así mismo, el artículo incluye la versión de Tello y sus impresiones acerca de sus investigaciones y la sorpresiva visita de la "comisión técnica". Por un lado Valcárcel señala que las excavaciones de Tello son una prueba inequívoca de la autonomía de la cultura Chavín, la cual no recibió influencia externa, menos de la cultura Maya. A la pregunta de cual fue la razón de la visita (hay que entender que "El Comercio" apoyaba a Tello), Valcárcel responde que "... para informar al gobierno ampliamente sobre lo hallado...no es posible mantener mas tiempo a las instituciones oficiales ignorando lo que se ha encontrado", luego refiriéndose a las excavaciones enfatiza "...el trabajo no es tan satisfactorio que digamos... los encargados de descubrir las ruinas son gente de poca práctica en tales menesteres y urge el envío de técnicos que secunden la labor de los arqueólogos...". Como podemos ver, Valcárcel critica abiertamente a Tello, cuestionando la labor de los obreros los cuales no estaban capacitados para dichas labores. En otra parte del texto critica la ubicación y forma en la que se abrió una de las unidades de excavación. Resulta paradójica la posición y opiniones de Valcárcel quien hasta esa fecha, nunca había participado en una excavación de gran envergadura como las que ya había realizado Tello en sitios como Paracas. Por su parte, Antúnez de Mayolo remarca también que las ruinas no tienen influencia Maya y aunque no se han excavado las otras huacas (que podrían tener influencia centroamericana), todo le inducía a pensar en que el sitio es totalmente Chavín. Aduce que "...no es gran cosa lo descubierto..." y que el gobierno deberá tomar acciones para la preservación del sitio. Indicó asimismo que haría un informe detallado de las investigaciones hechas en la zona. Para Tello, la visita realizada por ambos comisionados fue un ataque directo a sus trabajos, el cual concluyó en que se debían cancelar las excavaciones en Nepeña, por lo que en sus declaraciones publicadas en el mismo ar- 
tículo del diario limeño, argumenta que: “... no había razón que pudiera justificar una disposición que le privara del derecho de continuar libremente haciendo excavaciones que había empezado con su propio esfuerzo y acaso, con la colaboración de la Administración de la Hacienda San Jacinto y el pequeño auxilio de la señora Bentinck..." (Anónimo 1933). Del mismo modo se quejaba ya que a otros investigadores como Neverine y Langlois ${ }^{8}$ se les dejaba trabajar libremente sin la presencia de comisiones u otras disposiciones. Mas adelante menciona que esa comisión no era técnica en la materia y que él (Tello) había dedicado muchos años a la arqueología pasando su vida entre sitios y museos, con el objeto de ser algún día útil a la cultura histórica del país, entonces: “... iPor qué, pues, se trata de impedirme que ejerza mi profesión, cuando mis trabajos van a beneficiar a la colectividad? La respuesta, que además Tello sabía, era que el bloque conformado por Gutierrez de Quintanilla-Valcárcel trataba de acaparar la atención y el dominio del ejercicio de las ciencias sociales en el país, aprovechando la coyuntura política poco favorable a Tello, como sustento a sus acciones contra el otrora arqueólogo y diputado leguiísta.

En 1934, se celebraron 400 años de la fundación española del Cuzco y el gobierno peruano, influenciado en el plano cultural por Giesecke, Valcárcel y su grupo, no escatimó en aportar dinero para la limpieza de numerosos sitios arqueológicos como parte de las actividades de la gran celebración. Luis E. Valcárcel fue muy afortunado al tener en sus manos la oportunidad de orientar fondos económicos del gobierno para realizar trabajos de investigación y limpieza de los principales sitios arqueológicos del Cuzco, incluyendo Machu Picchu. Esta oportunidad, de volver triunfante desde Lima con fondos necesarios para embellecer y estudiar su ciudad, debe haber sido uno de los momentos de gloria de este intelectual orgánico. Esto se hace evidente en

8 Éste último había realizado hace poco investigaciones en el sitio de Paramonga, publicando posteriormente sus resultados en un folleto editado por el Museo Nacional titulado "Paramonga" y traducido por José Eulogio Garrido (Langlois 1938). el prólogo que hace al libro "Cuzco Histórico", editado por Rafael Larco Herrera en 1934 como parte del aniversario de dicha ciudad: "... Cuzco es la ciudad del futuro... en la que se opacará el milagro de la creación americana, del génesis neoinka". Al mismo tiempo publicaba en diversas fuentes la conceptualización y promoción del Cuzco como "Capital Arqueológica de Sudamérica” (Valcárcel 1934) El equipo, que residió por un año en Cuzco, estuvo conformado por el arquitecto Emilio Harth-Terré, el dibujante Alejandro Gonzáles y el fotógrafo Abraham Guillén (Matos et al. 1981: 289). Un dato interesante es que el personal de dicho proyecto carecía de arqueólogos profesionales. Varios informes y artículos fueron publicados en la Revista del Museo Nacional, a pesar de no contar con personal capacitado, tenían por título "Los Trabajos Arqueológicos en el departamento de Cuzco" (Valcárcel 1935) ${ }^{9}$. A pesar que los trabajos conducidos por Valcárcel generaron que el interés internacional se preocupe y admire a la antigua capital de los Incas; en su momento, Tello aprovechó para contra atacar y criticar abiertamente los trabajos que allí se realizaban. En un artículo publicado el 12 de marzo de 1934 en el diario "El Comercio", llama la atención que "... la manera inapropiada en la que se llevaban dichas excavaciones... encomendándolas a las acciones ciegas de un ejército de barreteros y capataces, ignorantes de toda norma y orientación científica..." (Tello 1934). Evidentemente Valcárcel y su equipo no estaban capacitados para excavar estratigráficamente los desmontes acumulados por el paso de los años sobre los muros Incas así como para catalogar los objetos asociados. En el primer informe publicado en la Revista del Museo Nacional sobre los trabajos del Cuzco, se presentan pocos datos y está lejos de ser un buen informe para la época. Por lo tanto, Tello tenía razón en criticar abiertamente las acciones que allí se realizaban. Del mismo modo no se había contado con los servicios de un arqueólogo que hubiera podido dirigir técnicamente las excavaciones. En este

9 Es interesante mencionar que 40 años más tarde, Luis E. Valcárcel menciona en sus Memorias que dichos trabajos fueron solamente de limpieza y conservación (Matos et al. 1981: 289) 
ambiente agitado y convulsionado de la arqueología y cultura peruana se formaron los lineamientos de la arqueología nacional. Sin embargo un hecho inesperado, cambia el rumbo de la situación cultural en el país.

\section{La Muerte de Emilio Gutierrez de QUINTANILLA}

El 27 de marzo de 1935 fallece el historiador Emilio Gutierrez de Quintanilla y con ello, una nueva coyuntura se genera en el Museo $\mathrm{Na}$ cional y sus institutos. Julio C. Tello y Luis E. Valcárcel parecen amistarse tras el fallecimiento del historiador. La evidencia de esta alianza parece ser un artículo que Valcárcel publica en un periódico local y en la Revista del Museo Nacional (Valcárcel 1935b, 1935c). Bajo esta perspectiva, podría haber sido Gutierrez de Quintanilla el elemento que separó a ambos intelectuales, a parte de las coyunturas ya descritas anteriormente. Creemos que Gutierrez de Quintanilla convenció a Valcárcel para que sea parte de la campaña y los obstáculos a los cuales fue sujeto Tello durante el periodo 1930-1935. Felizmente, para bien de la cultura peruana, ambos personajes dieron tregua a sus diferencias.

Coincidentemente el mismo año de la muerte de Gutierrez de Quintanilla, y a los 8 meses del evento, Valcárcel publica el 10 de noviembre de 1935 en el diario "La Prensa" de Lima un artículo titulado "Por Sud Perú, un viaje de gran trascendencia arqueológica" (Fig. 3). Allí Valcárcel da noticia de algo que se creía imposible: tanto él, como Tello viajaron juntos al sur peruano para realizar trabajos de exploración, excavación y supervisión de los trabajos arqueológicos de esa zona del Perú. De acuerdo a Valcárcel, realizaron excavaciones juntos cerca de Arequipa y en las inmediaciones de Pukará en Puno. Menciona que tuvieron la oportunidad de discutir varios aspectos. Asimismo, Tello verificó los resultados del proyecto realizado en el Cuzco entre 1933 y 1934 . Durante el viaje se llegaron a las siguientes conclusiones: 1) todos los materiales de la limpieza del Cuzco son de origen

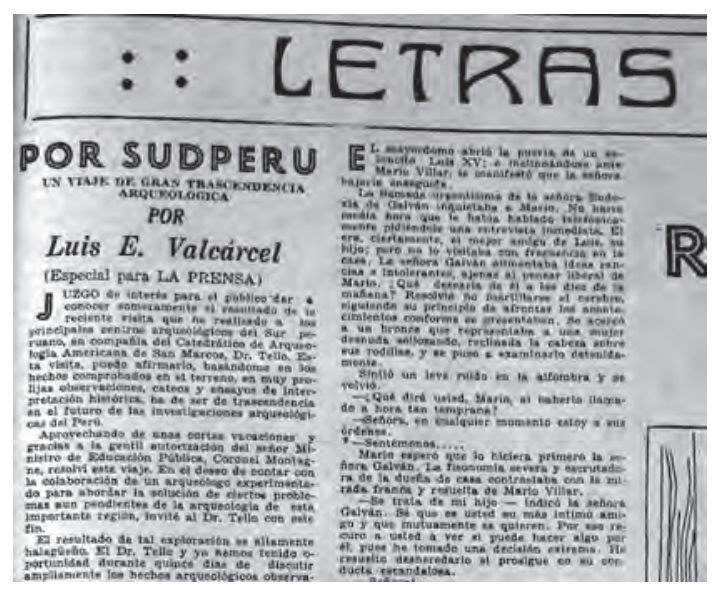

Figura 3: Portada del artículo periodístico publicado por Luis E. Valcárcel el 10 de Noviembre de 1935 en el diario "La Prensa" de Lima. Allí hace público el viaje que realizo con Julio C. Tello el mismo año.

Inca; 2) lo que se hizo en las campañas de 1933 y 1934 en el Cuzco fueron trabajos de "limpieza y conservación”; 3) Tello comprobó con "justeza e imparcialidad" que dichos trabajos han contribuido al estudio de trabajos arqueológicos posteriores y 4) los monumentos están a salvo y las colecciones en el Museo del Instituto recientemente formado. A estas conclusiones, de clara orientación conciliatoria y expiatoria para Valcárcel, se finaliza concluyendo que "...la mejor lección es el resultado profuso de la labor académica de los investigadores. Urge desarrollarla a corto plazo y con el apoyo de los poderes públicos" (Valcárcel 1935b). Este artículo fue reproducido al mismo tiempo en el número 2 del tomo IV de la Revista del Museo Nacional (Valcárcel 1935c). Aparentemente una vez muerto Quintanilla, ambos investigadores quedaron libres de tensiones y al menos institucionalmente, se hizo pública su conciliación en el plano académico. Es interesante comparar estos escritos con las escenas y situaciones que anteriormente ambos habían protagonizado. Con este evento se cierra una lucha por más de 5 años entre Tello y Valcárcel y se va a labrar el camino para una de las etapas más productivas en términos de consolidación académica e institucional de la arqueología y otras ramas de las ciencias sociales en el Perú. 
LIBROS, REVISTAS Y PERIÓDICOS: ANALIZANDO EL USO DE ESTAS FUENTES EN TELLO Y VALCÁRCEL

Una de las características más saltantes de los Latin American Organic Intellectuals (LAOI) es que muchas de sus publicaciones se convirtieron en trabajos clásicos de consulta. Del mismo modo muchas de sus contribuciones han dado pie a debates, organización de seminarios e incluso a reimpresiones de las ediciones originales o compilación en volúmenes dedicados a sus obras. En el caso específico de Julio C. Tello y Luis E. Valcárcel ambos han tenido una fértil producción aunque en el segundo caso ésta ha sido realmente impresionante (ver Tabla I). En esta sección pretendemos analizar el contexto en el cual se desarrollaron las publicaciones de ambos intelectuales.

A inicios del siglo XX las condiciones para las publicaciones de carácter académico no eran muy numerosas en el Perú. En 1906, la única revista especializada en historia y arqueología en Lima era la "Revista Histórica" la cual era el órgano publicitario del Museo de Historia Nacional. Sin embargo, como su nombre bien lo expresaba, tenía una clara tendencia a los estudios históricos a pesar que ocasionalmente y gradualmente fueron aumentando los trabajos de investigación arqueológica en sus páginas. Aparte de la "Revista Universitaria" editada por la Universidad Nacional Mayor de San Marcos en la cual se publicaban trabajos científicos en general, no existían otras revistas especializadas salvo el "Boletín de la Sociedad Geográfica de Lima” y el "Mercurio Peruano" en la cual se publicaban algunos trabajos de tendencia geográfica-descriptiva y a veces etnográfica. En el plano provincial el único dato que tenemos disponible es para el Cuzco. Dicha ciudad contaba con la "Revista Universitaria del Cuzco" y "La Sierra". La primera era al igual que su homónimo de San Marcos una revista de in- vestigación en general, mientras que la segunda fue creada por José Angel Escalante, el cual fue el primer órgano de la reforma universitaria de 1909 y tuvo una tendencia indigenista (Matos et al. 1981: 146). Es por ello que tanto Valcárcel como Tello van a estar directamente relacionados en la edición y producción de revistas especializadas en las que pudieron publicar sus trabajos, al mismo tiempo que daban la oportunidad a otros académicos para que den a conocer sus investigaciones. Podríamos argumentar que ambos intelectuales dieron origen a la tradición de la publicación de revistas arqueológicas y antropológicas en el país.

En esos tempranos años, el "Annual Report of the Bureau of American Ethnology", la revista "Harpers", las "Actas del Congreso Internacional de Americanistas" y las publicaciones del "Pan American Scientific Congress" eran fuentes muy prestigiosas para publicaciones arqueológicas e históricas en el plano internacional. Finalmente fueron los periódicos en los que se publicaron a diario muchos trabajos de estos intelectuales. De hecho, algunas de las contribuciones más importantes de Tello fueron publicadas en este medio (Burger 2009: 69). La gran ventaja de este tipo de publicaciones fue el bajo costo y sobre todo la gran audiencia a la cual se sometieron sus ideas e hipótesis. Como veremos mas adelante, la prensa fue usada como un medio de promoción personal, como un medio para expresar sus puntos de vista y como tribuna abierta para ventilar sus problemas y conflictos. Bajo esta perspectiva veremos también que la prensa, se valió de estos investigadores para vender su producto así como para servir a los grupos de poder que patentaban sus ediciones o a los cuales eran afines. Este feedback de intereses, configuró uno de los capítulos más interesantes de la naciente arqueología peruana.

Tabla I

\begin{tabular}{|l|r|r|r|}
\hline \multicolumn{1}{|c|}{ Intelectual } & Libros & \multicolumn{1}{c|}{$\begin{array}{c}\text { Artículos en libros, } \\
\text { revistas, etc. }\end{array}$} & \multicolumn{2}{c|}{$\begin{array}{c}\text { Artículos en } \\
\text { periódicos }\end{array}$} \\
\hline Julio C. Tello & 20 & 59 & 29 \\
\hline Luis E. Valcárcel & 29 & 367 & 159 \\
\hline
\end{tabular}


El primer trabajo publicado por Julio C. Tello fue un resumen de su tesis titulado "La Antigüedad de la Sífilis en el Perú" en la Revista Universitaria de la Universidad Nacional Mayor de San Marcos. Este trabajo fue reimpreso 4 veces en diferentes ediciones (Daggett y Burger 2009: 336; Espejo Nuñez 1954: 39). Cabe señalar que su tesis fue la primera en la historia de la facultad de San Fernando (UNMSM) en ser aceptada por aclamación (Lothrop 1948: 51; Espejo Nuñez 1954: 39,50-51; Daggett 2009: 11). Este fue también el debut de Tello como la promesa de un gran científico. El popular y reconocido tradicionalista Ricardo Palma fue quizá el mas importante de sus mentores, y fue precisamente el quien lo presentó con honores en los altos círculos sociales y académicos de la ciudad tras la brillante sustentación de su tesis (Daggett 2009: 12). Paradójicamente fue ese estudio lo que lo alejó de la medicina y lo acercó para siempre a la arqueología. Resulta interesante rescatar un detalle que ha pasado desapercibido a la hora de analizar el tema y contenido de la famosa tesis de Tello. Se ha postulado en base a las mismas confesiones que Tello hiciera a sus más cercanos discípulos, que fue el fortuito hallazgo de un artículo sobre la trepanación de cráneos en el antiguo Perú, lo que le motivó a interesarse en la medicina y arqueología. Lo interesante del caso es que algunas de las fotografías de los cráneos publicados, fueron los que él mismo recogió durante su infancia junto a sus hermanos cuando vivía en Huarochirí (Daggett 2009: 10). En 1905 realizó una expedición a los alrededores de su pueblo natal (Huarochirí y Yauyos) y tras colectar una nutrida colección de cráneos con evidencia de enfermedades, regresó a la UNMSM donde tras conversaciones con sus profesores decide cambiar su enfoque de estudios lingüísticos por la medicina con el objeto de analizar dichos restos (Daggett op. cit).

Analizando el contexto social de la ciudad de Lima en la primera década del siglo XX, es decir cuando Tello se encontraba desarrollando su investigación, encontramos un factor interesante. En esos años Lima sufría de una plaga de enfermedades venéreas, lo cual se convirtió en un problema de orden sanitario el cual debía remediarse. La alta tasa de desempleo, la crisis económica tras la guerra del Pacífico y el colapso de la economía del guano fueron algunos de los principales factores que ocasionaron esta situación (Huiza 2004: 156). En 1909 Debido a que el problema se agravaba constantemente, la Municipalidad de Lima mandó hacer un estudio el cual fue posteriormente publicado en "La Prostitución en la Ciudad de Lima” (Palacios 1992: 57, tomado de Huiza 2004: 156). Planteamos como hipótesis que ante la situación imperante en la ciudad, Tello decide orientar su tesis con un tema de actualidad, enfocando el estudio desde el punto de vista histórico. En un análisis de las condiciones que llevaron a Tello optar por el estudio específico de la sífilis, Teófilo Espejo Núñez indica lo siguiente: "Hubo de modificar su plan inicial, porque a medida que revisaba la documentación histórica iba creciendo en extensión el tema, hasta el extremo de verse en la necesidad de reducirlo a un solo aspecto, para examinarlo a conciencia. La orientación y consejos recibidos del norteamericano Dr. Albert S. Ashmead y, sobre todo, la amplitud del estudio de las intervenciones quirúrgicas observadas en su colección de 15000 cráneos y momias exhumadas, de los cuales mas de 1000 tenían deformaciones craneales, con anomalías, lesiones patológicas y más de 500 trepanaciones, influyeron para que abandonara tan atrevida empresa, limitando su tema "simplemente a los motivos que indujeron a los peruanos primitivos a la práctica de las trepanaciones. También en este punto -manifiesta Tello- era necesario restringir aún mas el objetivo: sólo la descripción de las trepanaciones demandaría grueso volumen; en consecuencia, sólo ofreció a la consideración de la Facultad los apuntes históricos tomados con la intención de probar la antigüedad de la sífilis en el Perú, por el papel que juzgó desempeñaba en las intervenciones quirúrgicas del cráneo en el periodo precolombino" (Espejo Nuñez 1954: 38). Esta información indica que Tello tuvo muchas opciones para orientar su tesis, pero se inclinó por demostrar la existencia de la sífilis en el Perú prehispánico, debido probablemente a la situación social imperante a su alrededor.

La hipótesis central de su trabajo fue demostrar la existencia de la sífilis en el Perú antes de la presencia española y que fue el estado social 
lo que orientó la propagación de la enfermedad (Espejo Nuñez 1954: 48). Con esta perspectiva, Tello no solo estaba solucionando un viejo debate, sino que contextualizaba históricamente una enfermedad que en ese mismo momento se encontraba atacando la ciudad. Esto se puede comprobar cuando Tello presenta en su tesis analogías entre casos clínicos y los objetos arqueológicos (Espejo Nuñez 1954: 45). Así, la proliferación de la enfermedad le permitía estudiar al detalle los síntomas y manifestaciones que luego buscó y comparó en los cráneos de Huarochirí. Bajo esta perspectiva, Tello sacó ventaja de la condición social para sobresalir en la universidad con un tema de actualidad al mismo tiempo que satisfacía su interés hacia la prehistoria peruana.

Este no es el único caso en que Tello usó las condiciones sociales y políticas para sacar provecho en su propio beneficio así como cumplir con sus altos valores de "peruanizar" al Perú. En 1921 el gobierno peruano celebró con gran fastuosidad el primer centenario de la independencia del país. Tello colaboró con el filántropo Víctor Larco Herrera para la conformación del Museo de Arqueología Peruana, del cual se convirtió en su primer director (Tello y Mejía Xesspe 1967: 115). Con el apoyo del rector de la UNMSM funda el Museo de Arqueología de la Universidad (Carrión Cachot 1948a: 11). Ese mismo año decide publicar, en base a sus exploraciones de 1919 el carácter autóctono de la civilización peruana en su libro "Introducción a la Historia Antigua del Perú” (Tello 1921). Una versión similar fue publicada en el diario "La Crónica" de Lima y se denominó "La Raza Peruana y la Civilización" el cual apareció el mismo 28 de julio de ese año. En ambas publicaciones Tello enfatiza que las culturas prehispánicas peruanas de desarrollaron autónomamente y que no necesitaron de la influencia centroamericana para alcanzar un alto grado de sofisticación. Es interesante que en un año con celebraciones tan especiales por la independencia nacional, donde el nivel de patriotismo y nacionalismo debieron estar en su clímax, Tello lance la revolucionaria idea del autoctonismo. De esta manera reivindicaba a los descendientes de los antiguos pe- ruanos, cumpliendo así con un viejo anhelo de devolver la autoestima a su propia raza. Tomando ventaja de las celebraciones, rechazaba con sólidos argumentos las propuestas iniciales de Max Uhle y le daba un nuevo giro a las investigaciones arqueológicas en el Perú. En corto, las publicaciones de Tello en 1921, acrecentaron la identidad nacional de los menos favorecidos, a la par que mostraba al resto de la población que debían sentirse orgullosos de su pasado, pues uno de los focos de la civilización mundial se había originado en los andes y fue hecha por los antiguos peruanos.

A lo largo de su carrera, Tello editó tres revistas en las que pudo publicar algunas de sus investigaciones así como las de sus discípulos y colegas en general. La primera de ellas fue la revista "Inca" cuyo primer número salió en 1923 y luego de 15 años se editó el segundo volumen, donde Tello publica un tratado sobre la tecnología de la cerámica mochica (Tello 1938). Uno de los artículos más extensos en la historia de la arqueología peruana debe ser el que publicó Tello en el primer volumen de "Inca" con el título de "Wiracocha". Se trata en verdad de un tratado de 250 páginas (227 páginas en el Volumen I, nro. 1 y 23 páginas en el Volumen I, nro. 2) donde Tello trata a fondo el tema de la religiosidad andina, analizando los antecedentes, discutiendo la iconografía, contrastando la información con algunos datos de sus exploraciones y excavaciones y finalmente usando información etnohistórica y etnográfica. Este trabajo debe constituirse como una de las obras maestras de Tello, la cual ha sido lamentablemente muy poco apreciada (no obstante, consultar Mesía 2006: 55 para un buen resumen). En esta revista se publicó además el artículo "La Mujer y el Niño en el Antiguo Perú”, redactado por Rebecca Carrión Cachot en 1923. Su trabajo estuvo orientado a "... ciertas actividades propias de la mujer, el rol que ella desempeñó en la civilización como obrera y como madre... la participación de la mujer en la civilización peruana, la lactancia, los cuidados que la madre prodigaba al niño durante la primera infancia..." (Carrión Cachot 1923: 329-330). De acuerdo a Bruce Trigger, la arqueología de género no se desarrollará hasta 
la década de los 70s en Noruega y en los Estados Unidos hasta la década de 1980 (Trigger 2007: 458). Así, una alumna de Tello y la revista que el fundó, fueron los primeros en la arqueología peruana y probablemente mundial en reconocer la importancia de los estudios de género en la arqueología y contextualizar la presencia de la mujer en las sociedades del pasado, usando artefactos arqueológicos y contrastándolos con las costumbres y tradiciones recuperadas en investigaciones etnográficas y etnohistóricas.

El contexto en que apareció su segunda revista denominada "Wiracocha" es peculiar. Debido a las agitaciones políticas que derivaron en el cambio del gobierno en 1930, Tello pierde el apoyo oficial del estado peruano y se gana automáticamente el desprecio del nuevo régimen. Tal como hemos explicado anteriormente, uno de los problemas más graves fue la falta de acceso a sus colecciones arqueológicas y en general la falta de trabajo, lo que puso a Tello en una verdadera crisis económica. En este contexto edita en 1931 la revista "Wiracocha" de la cual solo se publica un número. En dicha revista Tello publica un artículo lingüístico y otro acerca del análisis de una rara pieza de alfarería Nazca (Tello 1931b, 1931c). Rebecca Carrión Cachot y Toribio Mejía Xesspe, sus dos más cercanos colaboradores, publican trabajos sobre el material textil de Paracas y sobre la alimentación en el antiguo Perú. Saturnino Vara presentó un trabajo sobre una leyenda andina. Completaba el volumen un artículo sobre el vencejo en el arte decorativo de Nazca por Eugenio Yacovleff. Finalmente en 1940 edita la revista "Chaski" de la cual se publica un solo volumen y tres números.

La relación de Tello y la prensa escrita se puede remontar hasta sus años universitarios en San Marcos. Tello trabajaba en la Biblioteca Nacional bajo el auspicio de su mentor Ricardo Palma. En una oportunidad recibió la visita de dos extranjeros que habían participado en un congreso de Santiago de Chile. Estos estaban acompañados por Antonio Miró Quesada, uno de los dueños del diario "El Comercio" de Lima (Daggett 2009:12). A pesar que este pasaje de la vida de Tello ha sido constantemente mencio- nado por ser el momento en que consigue el contacto necesario para obtener la beca de Harvard, no se había enfatizado que fue además el momento en que establece un contacto imperecedero con los dueños del "El Comercio". Los Miró Quesada eran una poderosa familia en Lima y su periódico cada día cobraba mas importancia. Al mismo tiempo, ese diario apoyaba la tendencia política de Leguía y sus partidarios. Julio C. Tello, a su regreso de Estados Unidos y Europa, establece una alianza permanente con Leguía y por lo tanto con todos los círculos que dependían de el. Durante su vida, Tello publica 29 artículos periodísticos ${ }^{10}$. Resulta interesante ver el proceso de publicación de estos artículos. Richard Daggett ha enfatizado que Tello publicaba sus trabajos en el periódico con el objeto de dar a conocer a toda la ciudadanía sus investigaciones y sus ideas (Daggett 1992: 199). Nosotros hemos podido determinar además de la propuesta de Daggett, que el contenido y la cantidad de artículos publicados en este medio, estuvo íntimamente ligado a las coyunturas políticas y a la situación laboral de Tello. La producción periodística de Tello se puede dividir en dos grandes etapas. Por un lado, en el periodo que abarca los años 1906 a 1926, publica un total de 7 artículos periodísticos mayoritariamente en el diario "La Crónica”. De éstos, 5 son dedicados totalmente a la arqueología donde publica sus investigaciones sobre la trepanación de cráneos en el antiguo Perú, los sitios arqueológicos de las inmediaciones de Lima, una reflexión sobre el origen de la raza peruana y la civilización y finalmente el descubrimiento de los cementerios de Paracas (Fig. 4). La tendencia de estos artículos fueron básicamente dar a conocer el potencial, cantidad y calidad del patrimonio arqueológico. Del mismo modo, sirvió como un medio publicitario para dar a conocer a la gran audiencia los extraordinarios hallazgos de Paracas y sus nuevas

10 Richard Daggett (1992: 195) indica que Tello publicó 68 artículos periodísticos. Sin embargo, nuestro conteo, basado en la bibliografía publicada reciente por Daggett y Burger 2009, junto a otra fuente (Caballero 2007) indica que son 29 los artículos escritos por Tello, mientras que 39 de ellos son entrevistas, reportajes y notas a sus trabajos arqueológicos. 


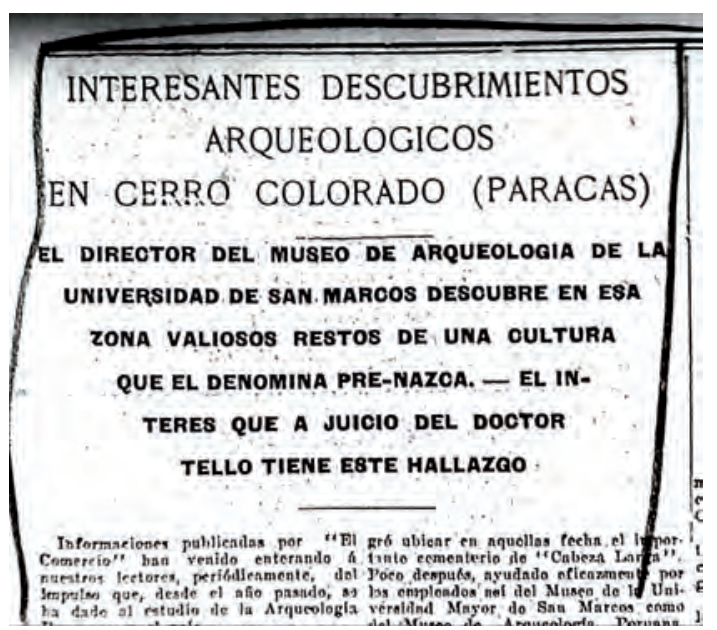

Figura 4: Portada del artículo publicado en el diario "El Comercio" sobre los hallazgos hechos por Tello en Paracas.

ideas sobre el origen de la cultura prehispánica de los andes centrales. Los dos artículos restantes de este período fueron el famoso escrito sobre la situación en la que recibió la sección de arqueología del Museo de Historia Nacional en 1913 y la respuesta tras los primeros enfrentamientos con Emilio Gutierrez de Quintanilla. Podríamos concluir que en esta primera etapa, Tello usa los medios de comunicación como una fuente de propaganda personal para integrar sus descubrimientos a la sociedad peruana, quien necesitaba conocer y valorar su patrimonio. Esta etapa coincide con un periodo políticamente favorable a Tello, pues abarca prácticamente el 80\% del denominado "Oncenio" de Leguía. No debemos olvidar que en 1917, Tello es elegido diputado de Huarochirí por lo que además contaba con un peso político propio en la capital. Así sus escritos no son críticas abiertas a la política cultural del país o en contra de la destrucción del patrimonio. No obstante, sus publicaciones van a promocionar el apoyo incondicional del gobierno peruano en sus investigaciones y el rol del estado en la formación de la conciencia e identidad nacional. Existe un hiato de publicaciones periodísticas escritas por él entre 1926 y 1929 (Daggett 1994). No obstante, en esos años publicó varios artículos en volúmenes y revistas así como importantes libros, no solo en el plano arqueológico como "Antiguo Perú"
(1929) sino su famosa "Reforma Universitaria", donde plantea la reestructuración de la educación en San Marcos, basando la formación del estudiante en la antropología y la medicina. Así mismo plantea la urgencia de establecer un sistema nacional de becas, para que los estudiantes peruanos sobresalientes tengan la oportunidad de viajar al extranjero (Tello 1928). En la segunda etapa que va de 1930 a 1946, Tello publica un total de 22 artículos periodísticos, 17 de ellos en "El Comercio" y los restantes en otros diarios. Esto indica el apoyo decidido de los Miró Quesada en tiempos en que Tello no tuvo apoyo político oficial. Esta etapa se puede subdividir en dos fases. La primera fase abarca de 1930 a 1935, donde la gran mayoría de estos escritos, a diferencia de los de la primera etapa, van a ser una queja constante contra los malos manejos del patrimonio, así como un medio para reclamar abiertamente las calumnias y acusaciones en su contra. Entre 1930 y 1935 debemos recordar que la situación política no fue favorable a Tello. Como hemos detallado anteriormente, el bloque Valcárcel-Gutierrez de Quintanilla se confabuló para atacarlo y desprestigiarlo. Los artículos publicados por Tello son un claro reflejo de la situación y en ellos clama por que se le deje trabajar, que se le reconozca su merecida posición y porque se tome más conciencia sobre la defensa del patrimonio arqueológico, debido a que el saqueo se había intensificado en muchos puntos del país. Muchos de los artículos fueron trabajados con astucia por el personal de "El Comercio". Por ejemplo, cuando se dio el caso de la suspensión de las excavaciones que Tello realizaba en Nepeña (1933), el diario publicaba las opiniones de la parte oficial, pero siempre concluían con la versión de Tello. En otras ocasiones muchos de los artículos de queja que Tello escribió, estuvieron en la portada del diario, siendo evidente el apoyo que recibió por parte de los antiguos leguiístas. En la segunda fase que abarca de 1936 a 1946, sus artículos presentan a un Tello maduro y en el clímax de su producción académica. Se puede ver la amplia perspectiva y visión sobre la arqueología del país, la cual se grafica en una entrevista que concedió a un periódico mexicano en 1944. Una 


\section{América Puede Llegar a ser un Pais de Indios}

\author{
No Habrá Mexicanos, Peruanos o Chilenos, \\ Sino Todos Indigenas, Augura Julio Tello
}

Por LUIs spota

LIMIA. Perú enero.- ISi los Estados Unidos no anulan la currura y el nacionalismo de los pueblos del Continente, la postguerra bo. rupira las fronteras politicas y raciales-y America toda será un solo gean pais de indios!

Es un indio, Julio C. Tello, qulen asegura que la oportunidad de su raza - in rnza india del continente- ha llegado, $y$ que la arqueolojgia, de la cual es él, en el Perú, un apóstol, contribuirá n "robustecer el nacionallsmo, el sentido hiatorico de nuestros pueblos".

Jullo C. Tello-que al lado de Caso, Noguera, Gnmio, trabaja intensamento por desentrahar los mistorios de los antiguos tlempos Indigenas-, hablá para EXCELSIOR, on nu luminoso santuarjo del Museo An tropológico de La Mngdalena, LIma, que dirige, sobre ol futuro do un ampueologín "amerleana", que muy pento "dejara de ser unn clenel muerin, para convertirse en un clenein millitante de primer orden" Tello, euya obrn se difunde por toda America y cuyo nombre es una gorntia. es indio; y afirma que ef Indilo sera, dentro de poco, el unich hombre del Nuevo Mundo, porqua vive en a liserra y porque nell lo liga un

clonnilidad". - Ya no habrá mexicanos, perun-

de las frases mas relevantes de Tello es que "... la arqueología ayudará a robustecer el nacionalismo, el sentido histórico de nuestros pueblos..." afirmaba que el periodo de la post-guerra no podía ser mas favorable al país "... la arqueología tiene un extraordinario porvenir, en la paz encuentra su oportunidad..." (Fig. 5). El término de la segunda guerra mundial se presentaba, en su opinión, como la mejor oportunidad debido a que tras una etapa de tiranía en la que el mundo quiso ser sometido a singularismo de una sola raza y sociedad, ahora despertaba el interés por conocer la diversidad de las razas y sus culturas, y en ello la antropología y la arqueología tendrían un rol prominente. El tiempo le dio la razón, pues desde 1942 a la fecha, la arqueología en el Perú ha cobrado un papel relevante. El último artículo que Tello escribirá en un periódico fecha el 17 de marzo de 1946, cuando llama la atención ciudadana sobre la destrucción a la cual venía siendo sujeto el sitio de Ancón (Tello 1946). Como podemos ver, ambas etapas se diferencian en la cantidad de publicaciones escritas. Mientras que en la primera publica 7, en la segunda triplica esa cantidad. Esto indica la necesidad de
Figura 5: Portada de entrevista dada por Tello al diario mexicano "Excelsior" en el cual augura que la arqueología jugara, al término de la segunda guerra mundial, un rol prominente en el conocimiento y difusión de la diversidad cultural del planeta.

Tello por usar los medios de la prensa impresa para publicar sus ideas y proyectos. A pesar que no dejó de publicar en libros y otras publicaciones especializadas, es evidente que en la segunda etapa el tema político motiva a Tello ha hacer mas público su trabajo quizá con el objetivo que se le retorne tarde o temprano su antiguo puesto de director del museo. Al mismo tiempo, al estar fuera del organigrama oficial de las instituciones que controlaban la cultura en el país, aprovechará su posición para criticar abiertamente a los que estaban en ella. Analizando la Tabla I, veremos que Tello priorizó la publicación de artículos en libros y revistas antes que la prensa escrita. Sin embargo reiteramos nuestra concordancia con Burger (2009: 69) que algunos de sus mas importantes trabajos fueron publicados en los periódicos.

Desde el punto de vista cuantitativo, Valcárcel tuvo una impresionante producción escrita. Debe tomarse en cuenta que vivió 96 años (fallece en 1987), y los datos presentados en la tabla I grafican su producción literaria hasta 1980. Tello vivió 67 años, por lo que gran parte de su producción académica es inédita y se encuentra en un magnífico archivo que custodia actualmente la UNMSM (Valcárcel Esparza 1966), el cual se viene publicando progresivamente (para una lista completa ver Dagget y Burger: 352 353). Sin embargo, comparando la producción de ambos entre 1908 y 1947 (fecha en que fallece Tello), se puede notar que Valcárcel siempre llevó la delantera en términos de publicaciones (Tabla II).

Luis E. Valcárcel se inició tempranamente en las publicaciones. Cuando aún era un niño, editaba un periódico llamado "El Toro" y luego otro denominado "El Heraldo" los cuales distribuía entre sus compañeros del colegio (Matos et al. 1981: 124). Su primera publicación oficial fue 
Tabla II. Producción escrita entre 1906 y 1947

\begin{tabular}{|l|r|r|r|}
\hline \multicolumn{1}{|c|}{ Intelectual } & Libros & \multicolumn{1}{c|}{$\begin{array}{c}\text { Artículos en libros, } \\
\text { revistas, etc. }\end{array}$} & \multicolumn{2}{c|}{$\begin{array}{c}\text { Artículos en } \\
\text { periódicos }\end{array}$} \\
\hline Julio C. Tello & 20 & 59 & 29 \\
\hline Luis E. Valcárcel & 12 & 190 & 130 \\
\hline
\end{tabular}

publicada en un periódico cuzqueño denominado "El Sol" donde discutió sobre la naturaleza y composición de la religión Inca. Luego publicaría regularmente en la revista "La Sierra" fundada por José Angel Escalante en 1909. Dada la naturaleza de la revista que tenía un enfoque de defensa indígena, los artículos de Valcárcel estuvieron orientados a plantear soluciones y propuestas que promuevan desde un plano intelectual la defensa y revaloración de la historia y raza indígena. La "Revista Universitaria" del Cuzco será otra fuente de publicaciones donde

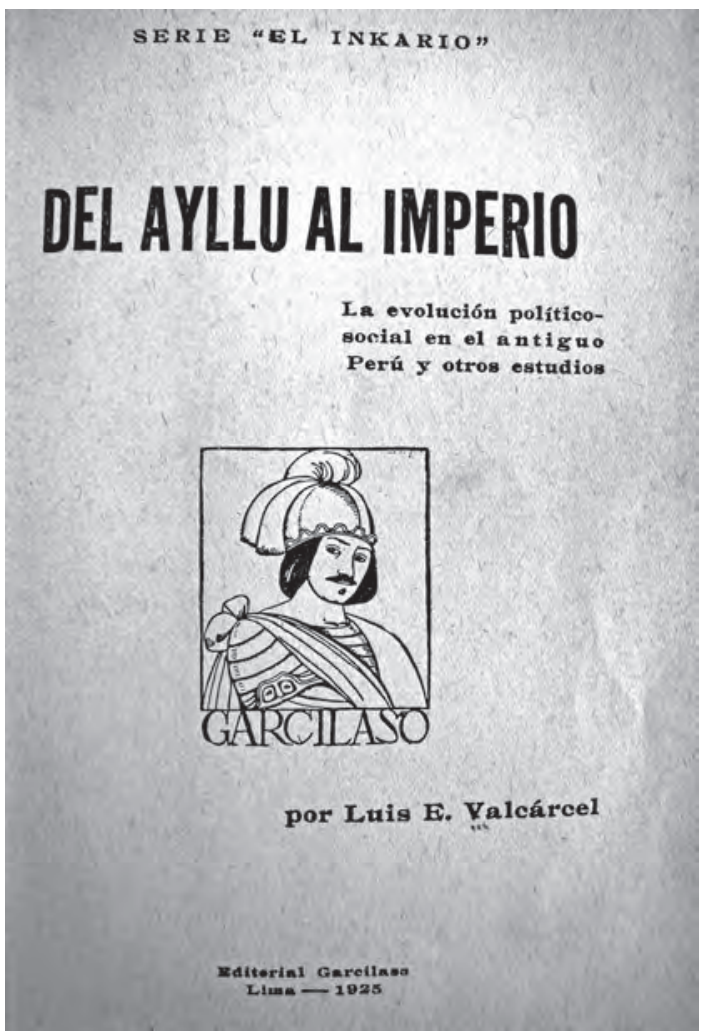

Figura 6: Portada del famoso libro publicado por Valcárcel en 1925 con clara tendencia indigenista. expresará sus propuestas e ideas en pro de la causa indígena, atacando abiertamente al gamonalismo quienes paradójicamente eran parte de su círculo social. Al mismo tiempo en esta revista publica sus primeros esbozos en arqueología, discutiendo temas como la ocupación Pre-Inca del Cuzco (Valcárcel 1924), la naturaleza de los petroglifos de la zona (Valcárcel 1925a) y su informe arqueológico de la zona de Pukará (Valcárcel 1925b). Es interesante señalar que 10 años más tarde visitará esa misma zona con Tello y ambos ejecuten excavaciones arqueológicas. Valcárcel ha sido reconocido como uno de los fundadores y amplificadores del movimiento indigenista (Tamayo 1980: 186). Así sus relaciones con otras agrupaciones indígenas le dieron la oportunidad de expresar sus ideas y puntos de vista en los órganos de publicación con los que estos grupos contaban. Ya hemos indicado que desde 1912 escribió para el diario indigenista de Abelardo Gamarra. En 1926 y producto de sus relaciones con José Carlos Mariátegui, publica un adelanto de lo que posteriormente será su famoso libro "Tempestad en los Andes". Esta contribución a la famosa revista "Amauta" va a ser la primera de una serie de artículos que lo consolidarán como uno de los líderes del movimiento indigenista De hecho, el paso fundamental de una esfera de acción regional a un campo mas amplio tomando como base Lima, originó lo que se ha denominado el "Indigenismo Militante" (José Luis Rénique, comunicación personal). Uno de los artículos mas reveladores es "Detrás de las Montañas", publicado en "Amauta" (Nro. 2) en 1926. Se puede advertir la intención de Valcárcel de dar a conocer la sierra a una población costeña que por la falta de medios de comunicación apropiados, no tenía una interacción constante con el paisaje y poblador serrano. Así mismo el desconocimiento del medio geográfico y la actitud del serrano en 
su medio, ocasionaba el desprecio de los costeños, quienes no podían entender la complejidad de sus habitantes. Por ello Valcárcel se detenía a explicar el paisaje, la raza, su filosofía: "Desparramados por la cordillera, arriba y debajo de las montañas, en las estribaciones de los Andes, en el regazo de los pequeños valles, cerca de las cumbres venerables, cabe a los ríos, a la orilla de los lagos, sobre el césped siempre verde, debajo de los kiswares vernáculos, en las quiebras de las peñas, oteando el paisaje, allí están los ayllus...". (Valcárcel 1926: 8) (Fig. 6). Luego tratará de realzar el valor y la naturaleza de la raza india: "La raza, (gracias a su fingir) protege su vitalidad, guarda intacto el tesoro de su espíritu, preserva su "Yo"” (Op. cit: 9). El carácter de resurgimiento y de reivindicación es siempre una constante en Valcárcel, y en este caso se hace evidente cuando justifica la actitud del poblador serrano: "El indio se cuida muy bien de la adquisición de sus dominadores... en cambio el se informará bien pronto de todos nuestros secretos de "hombres modernos". "Breve tiempo de aprendizaje bastará para que domine los mas complejos mecanismos y maneje con serenidad y precisión que le son características las maquinarias que requieren completa técnica". Finalmente uno de los grandes dilemas de este intelectual en los primeros años de su carrera, fue despreciar al elemento mestizo, pues como él mismo afirmaba eran: "gusanos perdidos en las galerías subcutáneas de este cuerpo en descomposición que es el poblacho mestizo...Todos los poblachos mestizos presentan el mismo paisaje: miseria, ruina: las casas que no se derrumban de golpe, sino que como atacadas de lepra, se desconchan, se deshacen lentamente, son el símbolo mas fiel de esta vida enferma, miserable, de las agrupaciones de híbrido mestizaje" (Valcárcel 1926: 9). Esta visión radical, va ir cambiando paulatinamente en su pensamiento, conforme vaya escalando en la estructura administrativa cultural del estado. Rénique ha señalado que ese proceso es parte de la "limeñización del provinciano cuzqueño” (José Luis Rénique, comunicación personal).

Figura 7: Uno de los tantos articulo redactados por Valcárcel para la prensa escrita extranjera. En este caso el destino fue el diario "La Prensa" de Buenos Aires, Argentina.

En 1923 dirigirá la famosa "Misión Peruana de Arte Incaico" la cual tuvo un éxito rotundo en los teatros de La Paz, Buenos Aires y Montevideo (Matos et al. 1981: 218). Aquella oportunidad, fue quizá la primera vez que el arte provincial del Cuzco se exhibía internacionalmente. Años mas tarde (1930) y con la obvia influencia de ser el nuevo director de los museos nacionales, Valcárcel haría su primera contribución en un diario extranjero. Este fue "La Prensa" de Argentina, con el cual iniciaría una fértil producción que se mantuvo por muchos años (Fig. 7). Los artículos publicados por este intelectual fueron muy diversos y abordaron una tendencia etnográfica, histórica, indigenista y hasta reflexiones sobre problemáticas arqueológicas. Se podría decir que mientras Valcárcel publicó artículos en "La Prensa", la audiencia bonaerense estuvo más actualizada e informada sobre la cultura peruana que los propios peruanos. La lista de diarios peruanos en los que Valcárcel publicó, fue ilimitada. Sin embargo uno de ellos estuvo ausente: "El Comercio" de Lima.

\section{LOS ESTUDIOS ETNOLOGICOS} EN EL PERU

Pot LUIS E. VALCARCEL

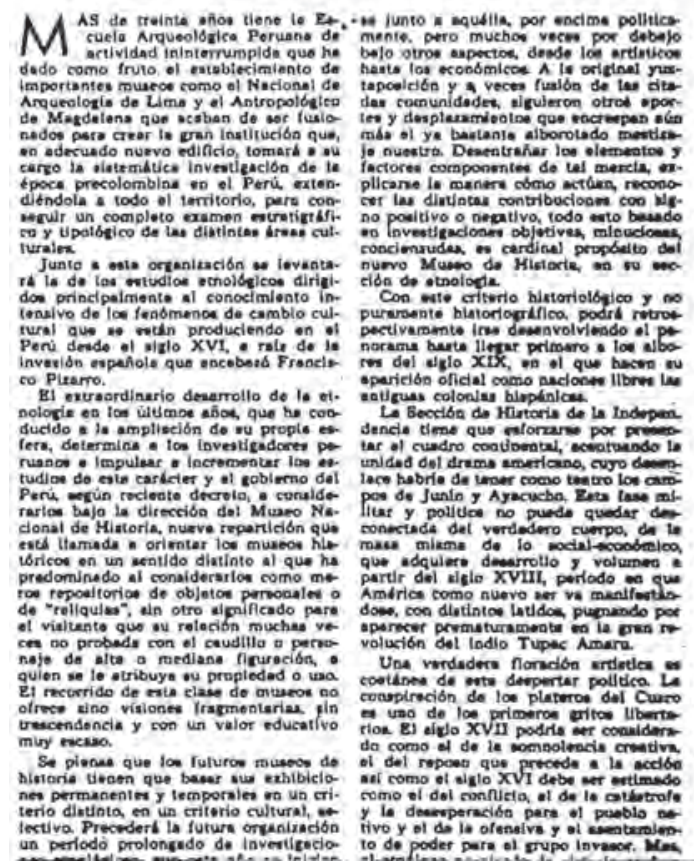


Desde su llegada a Lima en 1930 hasta 1945, periodo en que tuvo su mas prolija producción periodística, Valcárcel solo publicó 1 artículo en "El Comercio" de Lima en 1945. Cabe destacar que ese mismo año, fue elegido Ministro de Educación bajo el gobierno de Benavides. Es posible que la tendencia política de Valcárcel haya sido uno de los impedimentos para que publique en el periódico más importante de Lima. Creemos también que fue Tello quien le impidió publicar en dicho medio. Como hemos indicado la relación entre Tello y los Miró Quesada (dueños de "El Comercio") fue muy estrecha y es posible que el arqueólogo haya influenciado entre sus editores para evitar la publicación de los escritos de Valcárcel. Esto puede evidenciarse cuando tras la muerte de Tello en 1947, "El Comercio" luego de un periodo de 3 años, inicia relaciones con Valcárcel, al hacerle una entrevista fechada el 14 de diciembre de 1950. Tal fue la trascendencia para Valcárcel, que esa misma entrevista la publica en el tomo XIX-XX de la Revista del Museo Nacional que el mismo editaba. De los 25 artículos periodísticos que Valcárcel escribió entre 1950 y 1980, 15 de ellos serán en "El Comercio". Evidentemente la consolidación académica y trascendencia de este intelectual pesaron para que el diario limeño se interese por él, pero una vez mas podemos ver un caso en el que la política y las coyunturas sociales jugaron un papel predominante el cual puede ser "excavado" analizando las fuentes y los medios de publicación. A diferencia de Tello, Valcárcel va a publicar en muchos diarios internacionales, usando probablemente su influencia como la máxima autoridad oficial de las ciencias sociales en el Perú y posteriormente en su rol como Ministro del régimen del general Oscar $\mathrm{R}$. Benavides. Algunos de los que podemos listar son "El Heraldo" de Venezuela, American Weekly de Estados Unidos, "El Nacional" y "Excélsior" de México, "La Crónica" y "La Prensa" de Argentina, "The Illustrated London" de Inglaterra, "Mundo" de Uruguay, etc. Todos estos artículos tuvieron el rol de dar a conocer la cultura antigua del Perú, sus tradiciones y en algunas ocasiones su tendencia indigenista. Es interesante que Valcárcel haya sabido orientar la temática y el contenido de sus artículos cuando se trataba de publicar en medios extranjeros. En este sentido podría argumentarse que este intelectual fue un gran promotor de la cultura peruana en el extranjero, sentando las bases para un mayor interés por parte de la comunidad internacional en el país. En este contexto, sus trabajos de "limpieza y conservación" efectuados entre 1933 y 1934 en el Cuzco fueron el antecedente mas remoto para establecer una conexión directa entre la población y sus monumentos arqueológicos así como el inicio del turismo receptivo en la ciudad imperial, pues uno de sus principales objetivos fue impulsar el turismo para incrementar el interés por el pasado peruano. Esto se puede confirmar cuando en 1943 publica una guía turística denominada "Cuzco" editada en inglés en la cual promocionaba la ciudad imperial y sobre todo los monumentos arqueológicos que se habían limpiado en 1933-1934, incluyendo a la célebre Machu Picchu (Valcárcel 1943). Durante su larga carrera, Valcárcel editó algunas revistas como "Cuadernos de Arte Antiguo" los cuales fueron una serie de ediciones en las que se publicaron varios objetos que conformaban las colecciones del Museo Nacional. La revista "Garcilazo" fue el órgano de publicación de la "Asociación Nacional de Escritores, Artistas e Intelectuales Peruanos" o ANEIP que luchaba contra la ideología fascista que en esa época se hacía cada vez mas intensa en Europa. En esta revista, se publicaban artículos democráticos, de actualidad, temas de literatura, etc. (Matos et al. 1981: 330). A raíz de la fundación de una sede en Lima del Instituto Panamericano de Geografía, Valcárcel y otros intelectuales publicaron una revista denominada "Folklore Americano" de la cual se publicaron 17 números. En sus páginas se editaron muchos artículos etnológicos enfocados en las danzas, fiestas, mitos, leyendas entre otros aspectos de los andes sudamericanos. José María Arguedas fue uno de sus más recurrentes colaboradores (Matos et al. 1981: 370). No hay duda que la revista de mayor trascendencia fundada por Valcárcel es la "Revista del Museo Nacional", fundada en 1932 (Fig. 8). Esta publicación es la única sobreviviente de todo el conglomerado de publicaciones edi- 
tadas y creadas entre la década de los 20 y 30. Fue creada con el objetivo que se convierta en el órgano de publicación del Museo Nacional. Con esta revista como la publicación oficial de la arqueología e historia en el Perú, Valcárcel ganó mucho respeto en el extranjero pues se convirtió en un elemento de canje con otras publicaciones. En la Revista del Museo Nacional han publicado prácticamente todos los andinistas de renombre en el Perú. Siempre tuvo una tendencia receptiva a los trabajos publicados por investigadores extranjeros lo cual le dio un dinamismo y variedad desde sus inicios. En los primeros años de edición salían hasta dos números por año. Desde el Tomo XIII (1944) se viene editando anualmente y en algunos casos cada dos años. Las publicaciones que dieron la consagración internacional a Valcárcel fueron tres artículos publicados en el famoso Handbook of South American Indians publicado por Julian

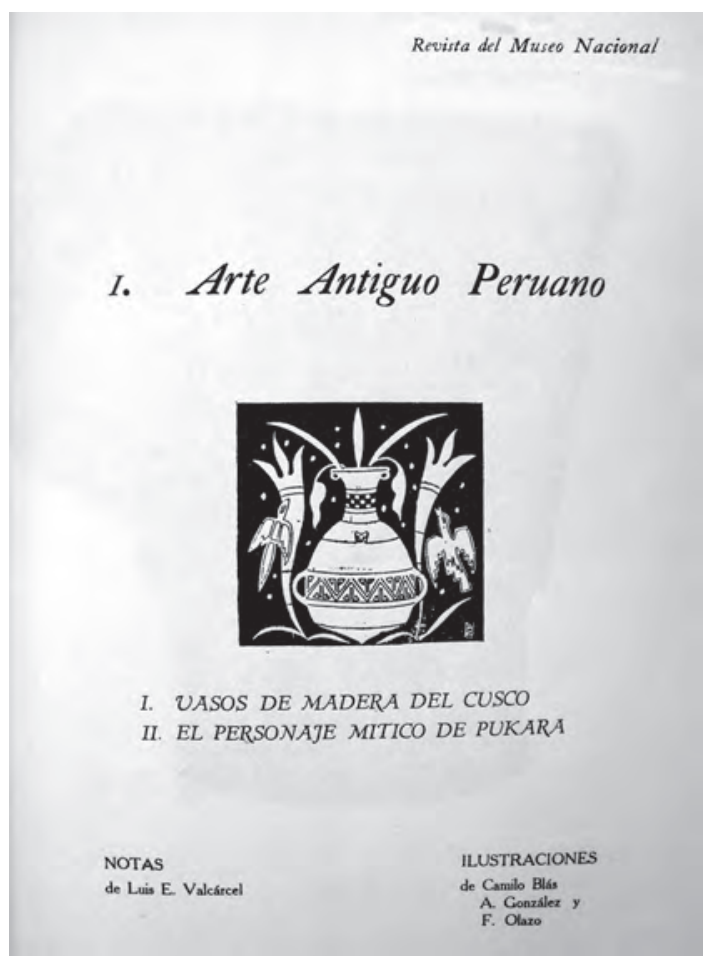

Figura 8: Portada del primer artículo publicado en el primer número de la "Revista del Museo Nacional", único medio impreso que subsiste hasta el día de hoy desde los tiempos de Tello y Valcárcel.
H. Steward. Dos de ellos fueron etnológicos, enfocándose en los calendarios ceremoniales cíclicos de los andes y la existencia de los mercados andinos. Sobre el último punto en particular se ha desarrollado un intenso debate el cual ha generado la publicación de volúmenes dedicados exclusivamente a este tema (Larson and Harris 1995; Esteva 1970, Valcárcel 1946d).

\section{Comentarios Finales}

El presente ensayo ha tenido el objetivo de discutir algunos aspectos a los que no se les ha prestado mayor atención sobre la vida de Julio C. Tello y Luis E. Valcárcel: el uso del poder político para maniobrar en favor de sus intereses académicos y personales. Así mismo presentamos un primer análisis comparado sobre la obra escrita de ambos autores, analizando fuentes de publicación, tendencia y mensaje, etc. No hemos tratado de hacer una síntesis de sus principales trabajos, los cuales hemos preferido no incluirlos, pero si discutimos el manejo que le dieron a las fuentes de publicación que tuvieron disponible, especialmente aquella relacionada a la prensa. Si bien es cierto en el caso de Tello, Richard Daggett viene realizando una importante reconstrucción biográfica en base a los archivos periodísticos y otras valiosas fuentes, no se había elaborado hasta la fecha un análisis de la naturaleza/tendencia de las publicaciones que Tello realizó en los medios periodísticos. Esperamos que las "fases" y "tendencias" que hemos demostrado en este ensayo así como su relación con los problemas políticos y personales que $\mathrm{Te}$ llo tuvo durante su vida se presten a una discusión futura a los interesados en el tema. Hemos ofrecido una primera aproximación al estudio de los documentos publicados por Valcárcel en los periódicos nacionales y extranjeros debido a que su obra es generalmente abordada desde la perspectiva indigenista. Debemos recalcar que nuestro trabajo en este caso es muy preliminar y existe una riquísima fuente de información, la cual merece mayor atención. El rol que cumplió el diario "El Comercio" de Lima, no solo como un medio de publicación para Tello (Dag- 
get 2009), pero como un medio de subsistencia académica y de defensa, nos ha permitido contextualizar la situación política del momento. Por esa razón es que Valcárcel, al ser un "enemigo" de Tello durante el periodo 1930-1935 no tuvo la oportunidad de publicar en dicho periódico. Del mismo modo, hemos tratado de abordar la problemática que surgió entre Tello y Valcárcel durante el periodo que les tocó convivir en la misma ciudad y en el mismo centro de trabajo. Creemos haber demostrado que uno de los factores de distanciamiento, a parte de los problemas suscitados por la dirección del museo, fue la figura de Emilio Gutierrez de Quintanilla. En este sentido es interesante que tras la muerte de Gutierrez de Quintanilla, ambos intelectuales se hayan amistado a iniciativa de Valcárcel, realizando incluso un viaje juntos. El "background" de cada uno de estos intelectuales va a ser determinante para las acciones que van a realizar durante su vida. Por un lado Tello, el indio-mestizo provinciano va a reivindicar su raza creando una nueva historia, la historia prehispánica en base a los estudios arqueológicos. Del mismo modo, aprovechando el poder político que tuvo por varios años, sentará las bases legales para la preservación del patrimonio arqueológico del país. Tello entendió su rol dentro de la historia de la arqueología y por ello se dedicó a realizar múltiples expediciones a lo largo y ancho del país. Con ello estableció un primer "estado de la cuestión" de los componentes materiales de las culturas prehispánicas que habitaron los andes centrales. La forma en que dejó ordenado su archivo, indica que tenía en mente dedicarse los últimos años de su vida a publicar todos los trabajos que había realizado. Tello supo usar inteligentemente los medios periodísticos, no solo para dar a conocer el patrimonio nacional, sino también para promocionar su carrera, denunciar atentados contra el patrimonio arqueológico y su persona, así como un medio de "subsistencia escénica" durante la época en que Valcárcel acaparó el control (y con ello la prensa) de la cultura a nivel nacional. Otro aspecto es que Tello usó sus publicaciones e investigaciones para cobrar relevancia nacional al mismo tiempo que acrecentaba la identidad de los peruanos (Burger 2009). Luis E. Valcárcel podría considerarse el gran organizador y el intelectual que institucionalizó la cultura en el país. Desde sus diferentes posiciones políticas, Valcárcel aprovechó las circunstancias no para enriquecerse, sino para enriquecer la historia y la cultura del país. En esa línea podemos argumentar que Valcárcel tuvo ese ímpetu constante de querer controlar todas las dependencias de cultura del medio pero con el objetivo de acrecentar, reorganizar e inyectar el componente de investigación. A el se deben el uso pionero de la etnohistoria como una rama de la historia para estudiar el contexto social, político y económico que las fuentes documentales podían ofrecer. Esta perspectiva va a ser continuada y perfeccionada luego por John V. Murra (Enrique Mayer, comunicación personal). Valcárcel también va a ser el responsable de la creación de la Etnología en el Perú y de su enseñanza en las universidades. A diferencia de Tello, logró materializar la propuesta para brindar oportunidades a los jóvenes investigadores nacionales de salir al extranjero y perfeccionar sus estudios. La perspectiva cultural de Valcárcel fue más amplia que la de Tello en cuanto se preocupó de las artes plásticas, el teatro, la música, pues veía todos estos elementos como un solo componente de la cultura peruana. La creación del Instituto de Artes Peruanas dirigido por J. Sabogal y luego por J.M. Arguedas, ha permitido que los investigadores contemos con uno de los archivos mas ricos de tradiciones, mitos, leyendas, danzas, canciones, etc. de los pueblos andinos del Perú. Desde su posición de ministro de educación, trató de aplicar ciertas ideas indigenistas, pero tropezó con la dura realidad. No obstante, hoy en día muchos colegios enseñan en Quechua y al menos casi todos los centros educativos del país se han dedicado a recopilar las tradiciones de sus pueblos (preferentemente danzas y leyendas), cumpliendo así uno de los objetivos de la propuesta de Valcárcel. Lo que falta ahora es una gran compilación de todos esos trabajos en un único archivo que luego permita su difusión a nivel nacional. 
Tello y Valcárcel son dos modelos de intelectuales que aportaron fructíferamente durante su vida al desarrollo de las ciencias sociales del Perú. Sus enfrentamientos y contradicciones estuvieron marcados por una competencia en la que cada uno quiso brillar más que el otro. No obstante, sus actos dentro de este contexto, siempre estuvieron orientados a mejorar las condiciones de la investigación en el país.

\section{Agradecimiento}

Este ensayo se basa en un manuscrito hecho por el autor el cual fue presentado al seminario "Latin American Organic Intellectuals" dictado en la primavera del 2009 en el departamento de Antropología de la Universidad de Yale. Mi gratitud va hacia los profesores que dictaron aquel seminario: Richard L. Burger y Enrique Mayer. Cada semana de aquel semestre, pudimos explorar a fondo el pensamiento vida y obra de renombrados intelectuales latinoamericanos, lo cual me permitió comprender un poco más el panorama social y político de la arqueología. Pero más importante aún, fue conocer en algunos casos y profundizar en otros, mis conocimientos sobre la obra de aquellos intelectuales. En ese sentido, Enrique y Richard, condujeron magistralmente los temas y la discusión entre los participantes de la clase. Así mismo, fueron muy valiosas las observaciones y conocimientos proporcionados por José Luis Rénique, quien fue invitado por los profesores del seminario con el objeto de tener una perspectiva más amplia de Luis E. Valcárcel.

Todos los errores e ideas de este manuscrito, son de entera responsabilidad del autor y no necesariamente grafican las opiniones de los participantes de aquel seminario.

\section{Bibliografía}

Anónimo

1906 Revista Histórica.

1933 Las Ruinas del Valle de Nepeña. Lo que refieren los doctores Tello, Valcárcel y Antúnez de Manolo. Se trata de restos de la civilización Chavín. Los dos últimos coinciden en sus apreciaciones. Diario "El Comercio" de Lima, 05 de octubre.

Basadre, Jorge

1946 Historia de la República del Perú. Editorial Universitaria. Lima, Perú.

Bennett, Wendell

1939 "Archaeology of the North Coast of Peru". Anthropological Papers of the American Museum of Natural History, Vol. 37, Part I. New York.

Bonfil, Guillermo

1981 Utopía y Revolución: el pensamiento político contemporáneo de los indios en América Latina. Editorial Nueva Imagen.

Burger, Richard

2009 "The Intellectual Legacy of Julio C. Tello". In: The Life and Writings of Julio C. Tello. Americas's first indigenous archaeologist. Richard L. Burger, editor. Pp. $65-$ 88. University of Iowa Press, Iowa City

Caballero, César A.

2007 Vida y Obra de Julio C. Tello. Arteidea editores. Lima, Perú.

Carrion Cachot, Rebecca

1923 "La Mujer y el Niño en el Antiguo Perú (Notas Arqueológicas)". Inca. Revista de Estudios Antropológicos órgano del Museo de Arqueología de la Universidad Mayor de San Marcos de Lima Vol I, pp. 329-354. Lima, Perú.

1948a "Julio C. Tello y la Arqueología Peruana". Revista del Museo Nacional Vol 2 nro. 1, pp. 7-34.

1948b "Las Teorías arqueológicas del Dr. Julio C. Tello". Mercurio Peruano. Revista Mensual de Ciencias Sociales y Letras. Año XXIII, junio de 1948 nro. 255. pp. 195-198.

Collier, Donald

1955 "Cultural Chronology and Change as Reflected in the Ceramics of the Virú Valley, Peru". Feldiana: Anthropology, Vol 43. Chicago Natural History Museum.

Daggett Richard

1987 "Reconstructing the evidence for Cerro Blanco y Punkurí". Andean Past 1: 111 163. 
1992 "Tello, the press and Peruvian Archaeology". In Rediscovering our past: essays on the history of American archaeology. Jonathan E. Reyman, editor. Pp. 191-201. Brookfield, Avebury.

1994 Tello's "Lost Years": 1931-1935. Paper presented at the 13th Annual Norteast Conference on Andean Archaeology and Ethnohistory. Ithaca College, Ithaca New York. October 15-16 1994.

1996 The Libertad Campaign against Tello: setting the record straight. Paper presented at the 15 annual northeast conference on andean archaeology and ethnohistory, Saturday october 19th 1996, Rainey auditorium. University of Pennsylvania, Museum of Archaeology and Anthropology Philadelphia.

2009 "Julio C. Tello: An Account of His Rise to Prominence in Peruvian Archaeology". In: The Life and Writings of Julio C. Tello. Americas's first indigenous archaeologist. Richard L. Burger, editor. Pp. 7-54. University of Iowa Press, Iowa City

Daggett, Richard; Richard L. Burger

2009 "An annotated bibliography of Julio C. Tello". In: The Life and Writings of Julio C. Tello. Americas's first indigenous archaeologist. Richard L. Burger, editor. Pp. 335 354. University of Iowa Press, Iowa City

Deler, Jean Paul

1975 Aspectos del crecimiento de la capital peruana Lima 1940-1970. Centro de Investigaciones Geográficas. Lima, Perú.

Espejo Nuñez, Teófilo

1954 "La Antigüedad de la Sífilis en el Perú, de Julio C. Tello". América Indígena Vol. XIV, nro. 1, pp. 37-51.

Esteva, Claudio

1970 "Un Mercado en Chinchero, Cuzco". Anuario Indigenista Vol. XXX: 213-254.

Ford, Alfred; Gordon R. Willey

1949 "Surface Survey of the Virú Valley, Peru". Anthropological Papers of the American Museum of Natural History Vol. 43: Part I. New York.

Gutiérrez de Quintanilla, Emilio

1922 El Manco Cápac de la arqueolojía peruana: Julio C. Tello (Sr. De Huarochirí) contra Emilio Gutierrez de Quintanilla. Lima, Perú.
Huiza, Jose Luis

2004 "Reconstrucción Nacional y República Aristocrática". In El Perú Republicano, de San Martín a Fujimori. José Luis Huiza, Raúl Palacios and José Valdizán, editors. pp. 119-204. Fondo de Desarrollo Editorial. Universidad de Lima. Lima, Perú.

Kaulicke, Peter

1998 Max Uhle y el Perú antiguo. Fondo Editorial Pontificia Universidad Católica del Perú. Lima, Perú.

Kroeber, Alfred

1924 The Uhle pottery collections from Chincha. University of California Press. University of California. Berkeley, California.

1925 The Uhle pottery collections from Moche and The Uhle pottery collections from Supe. University of California Press. University of California. Berkeley, California.

1926 The Uhle pottery collections from Chancay. University of California Press. University of California. Berkeley, California.

Langlios, Louis

1938 "Paramonga". Revista del Museo Nacional, vol VII, nro. 1, pp. 21-52.

Larco Herrera, Rafael

1934 Cuzco Histórico. Homenaje a la ciudad de todos los tiempos en la cuarta centuria de su fundación española. Casa editora La Crónica y Variedades S.A. LTDA.

Larson, Brooke; Olivia Harris

1995 Ethnicity, markets, and migration in the Andes. At the Crossroads of History and Anthropology. Duke University Press, Durham and London.

Leguia, Augusto B.

2006 Para la Patria y por la Patria. Prólogo y notas de Enriqueta Leguía Olivera.

Lothrop, Samuel

1948 "Un Recuerdo del Dr. Julio C. Tello y Paracas". Revista del Museo Nacional de Antropología y Arqueología No. 1. Lima, Perú.

Matos Mar, José; José Destua; José Luis Renique

1981 Memorias / Varcárcel. IEP. Lima, Perú.

Mesía, Christian

2006 "Julio C. Tello: Teoría y Práctica en la Arqueología Andina”. Arqueología y Sociedad nro 17, pp. 49-66. Museo de Ar- 
queología y Antropología de la Universidad Nacional Mayor de San Marcos.

Mejia Xesspe, Toribio

1948 "Apuntes Biográficos sobre el Dr. Julio C. Tello". Revista del Museo Nacional Vol. 2 nro. 1, pp. 35-49.

Murra, John V.

2002 El Mundo Andino. Población, medio ambiente y economía. Fondo Editorial de la Pontificia Universidad Católica del Perú y el Instituto Peruano de Estudios Andinos. Lima, Perú.

2009 "The Internacional Relevante of Julio C. Tello". In: The Life and Writings of Julio C. Tello. Americas's first indigenous archaeologist. Richard Burger, editor. Pp. 55-64. University of Iowa Press, Iowa City

Palacios, Raúl

2004 "De Leguía a Fujimori: La Trayectoria del Poder Político en el Perú, 1919-2000”. El Perú Republicano, de San Martín a Fujimori. José Luis Huiza, Raúl Palacios and José Valdizán, editors. pp. 205-358. Fondo de Desarrollo Editorial. Universidad de Lima. Lima, Perú.

Ponce Sanchez, Hernan

195750 Anécdotas del Sabio Tello. Editorial La Universidad. Lima, Perú.

Rowe, John H.

1954 Max Uhle, 1856-1944. A memoir of the father of Peruvian Archaeology. University of Calfornia Press. Berkeley and Los Angeles.

Tamayo, José

1980 Historia del Indigenismo Cuzqueño, siglos XVI-XX. Instituto Nacional de Cultura. Lima, Perú.

Tello, Julio C.

1913 Presente y Futuro del Museo Nacional. Sanmarti y CIA. Lima, Perú.

1928 Reforma Universitaria. Sanmarti y CIA. Lima, Perú

1929 Antiguo Perú, primera época. Editado por la Comisión Organizadora del segundo Congreso Sudamericano de Turismo. Lima, Perú.

1930 "Una Carta del Director del Museo de Arqueología Peruana”. Diario El Comercio de Lima, 16 de septiembre de 1930. 1931a "Nota Editorial”. Wira-Kocha Vol I, nro. 1, pp. 1-3. Lima, Perú.

1931b "Sistema Fonético de las lenguas indígenas del Perú". Wira-Kocha Vol I, nro. 1, pp. 4-8. Lima, Perú.

1931c "Un Modelo de escenografía plástica en el Arte Antiguo Peruano". Wira-Kocha Vol I, nro. 1, pp. 87-112. Lima, Perú.

1932 "La Defensa de nuestros tesoros arqueológicos”. Diario El Comercio de Lima, 26 de mayo.

1934 "Las Excavaciones Arqueológicas en el Departamento del Cuzco". Diario El Comercio de Lima, 12 de marzo.

1938 "Arte Antiguo Peruano. Album fotográfico de las principales especies arqueológicas de cerámica existentes en los $\mathrm{Mu}$ seos de Lima. Primera Parte. Tecnología y Morfología”. Inca. Revista de Estudios Antropológicos órgano del Museo de Arqueología de la Universidad Mayor de San Marcos de Lima Vol II. Lima, Perú.

1942 "Aportes de los Estados Unidos a la Arqueología Peruana. Peruanidad". Órgano Antológico de pensamiento nacional Vol II, nro. 6, pp. 483-485.

1946 "Los Tesoros Arqueológicos de Ancón". Diario El Comercio de Lima, 17 de marzo.

Tello Julio C.; Toribio Mejía Xesspe

1967 "Historia de los Museos del Perú 1822. 1946”. Arqueológicas No. 10. Publicaciones del Instituto de Investigaciones Antropológicas. Museo Nacional de Antropología y Arqueología. Universidad Nacional de San Marcos. Pueblo Libre, Lima, Peru.

Trigger, Bruce

2007 A History of Archaeological Thouht. Second Edition. Cambridge University Press.

Valcárcel Esparza, Carlos Daniel

1966 El Archivo Tello. Lima, Perú.

Valcárcel Vizcarra, Luis Eduardo

1924 "El Cuzco Pre-Colombino. Impresión Panorámica. La edad Pre Inca”. Revista Universitaria. Órgano de la Universidad del Cuzco nro. 44-45, pp. 16-29.

1925a "Los Petroglifos del Cuzco, Prehistoria Americana”. Revista Universitaria. Órga- 
no de la Universidad del Cuzco nro. 47, pp. 26-29.

1925 b "Informe sobre la exploración arqueológica de Pukara". Revista Universitaria. Órgano de la Universidad del Cuzco nro. 48, pp. 14-21.

1926 "Detrás de las Montañas". Amauta nro. 1, Año 1, pp. 20-22.

1932 "Prólogo". Revista del Museo Nacional T. I, nro. 1, pp. 3-6.

1934 "Prefacio". In Homenaje a la ciudad de todos los tiempos en la cuarta centuria de su fundación española. Rafael Larco Herrera, editor, pp. 1-2. Casa editora La Crónica y Variedades S.A. LTDA.

1935a "Los Trabajos arqueológicos en el departamento del Cuzco". Revista del Museo Nacional T. IV, nro. 1, pp. 1-24.

1935b "Por Sud-Perú. Un Viaje de gran trascendencia arqueológica". Diario La Prensa de Lima, 10 de noviembre.

1935c "Por Sud-Perú. Un Viaje de gran trascendencia arqueológica". Revista del Museo Nacional T. IV, nro. 2, pp. 205-206.

1943 Cuzco. Empresa Gráfica T. Scheuch. Lima, Perú.

1945 "Hambre". Diario El Comercio de Lima, 24 de junio. 1946a "Política y etnología”. Revista del Museo Nacional, Vol XV, pp. 3-13.

1946b "Cuzco Archaeology". In Handbook of South American Indians, Vol II. Washington. Julian Steward, editor. Pp. 177182.

1946c "The Andean Calendar". In Handbook of South American Indians, Vol II. Washington. Julian Steward, editor. Pp. 471476.

1946d "Indian markets and fairs in Perú". In Handbook of South American Indians, Vol II. Washington. Julian Steward, editor. Pp. 477-482 1967 La Educación del Campesino. Serie Problemas de la Educación Peruana 4. Segunda edición. Universidad Nacional Mayor de San Marcos. Facultad de Educación.

Willey, Gordon

1988 Portraits in American Archaeology. Remembrances of Some Distinguished Americanists. University of New Mexico Press. Albuquerque.

Willey, Gordon; John M. Corbett

1954 Early Ancón and Early Supe Culture. Chavin Horizon Sites of the Central Coast. Columbia University Press, New York. 